\title{
anomalies géostatiques stables et instables dans le cas du sel étude par simulation en centrifuge
}

\author{
stable and unstable geostatic anomalies in the case of salt, \\ a study by centrifuge simulation
}

\author{
Amos Zelikson \\ Laboratoire de mécanique des solides*
}

\section{Résumé}

L'article présente les résultats des essais sur modèles réduits centrifugés pour étudier l'initialisation et l'évolution des dômes de sel. Des solides tendres (argiles chargées et non chargées, gélatine,...) représentent le sel et la roche à l'échelle du temps géologique. La similitude est basée sur le modèle de Bingham. Les contraintes et déformations sont observées et filmées. La photoélasticité est utilisée pour les contraintes. La sécurité de diverses configurations est étudiée.

\footnotetext{
Abstract

The paper presents the results of centrifuge model tests studying the triggering and development of salt domes. Soft solids (loaded and unloaded clays, geltaine,...) represent the salt and the rock on a geological time scale. The similitude is based on the Bingham model. The stesses and deformations are observed and filmed. Photoelasticity is used for the stresses. The safety of various configurations is studied.
}

\footnotetext{
- École polytechnique, 91128 Palaiseau cedex.
} 


\section{INTRODUCTION}

L'article présente les résultats des essais sur modèle réduit, effectués sur la grande centrifugeuse du C.E.S.T.A. près de Bordeaux. Un grand nombre d'évolutions géologiques peuvent être expliquées par des anomalies géostatiques. Les méthodes de simulation par centrifugeuse, appliquées ici dans le cas du sel, sont bien adaptées à l'étude de certaines de ces évolutions.

La présente étude est motivée par l'examen de la sûreté d'un enfouissement de déchets radioactifs de haute activité. Il s'agit notamment d'imaginer un scénario d'évolution, pour une période de l'ordre de 1000 à 100000 ans qui comporte l'hypothèse de la formation et du développement d'un dôme de sel.

Une part importante des questions soulevées sont d'ordre qualitatif : une couche de sel comportant une inclusion de déchets chaud peut-elle développer un dôme? Une couche rigide et mince peut-elle arrêter le développement d'un dôme? Un dôme de sel parviendra-t-il nécessairement jusqu'au voisinage de la surface libre? Le cadre méthodologique adéquat dans lequel cet ensemble de questions doit être posé est lapproche "morphologique ", au sens de la Gestaltthéorie développée dans les années 1920. Dans cette approche, le dôme est considéré comme un ensemble, une « forme » qui varie: l'objet de l'étude est sa naissance et son évolution (on doit rapprocher ces remarques de la présence, dans l'ouvrage de René THOM sur la théorie des catastrophes [1], du problème de l'existence des dômes de sel).

Les dômes de sel ne peuvent être complètement étudiés pour le problème qui nous préoccupe par l'observation in situ. D'une part, nous sommes intéressés par la dynamique du phénomène pendant une période de l'ordre de $10^{5}$ à $10^{6}$ années; par ailleurs, la mesure détaillée qui serait nécessaire n'est pas envisageable, compte tenu des profondeurs mises en jeu. La figure 1 montre quelques exemples de dômes. On remarquera l'absence d'informations au-delà d'une certaine profondeur.

L'approche des phénomènes par le calcul (méthodes analytiques ou numériques) est également limitée par les difficultés mathématiques considérables du problème : un coup d'œil sur les photos figurant dans le présent article donnera une idée de la complexité de l'évolution réelle du système.

Il résulte des remarques qui précèdent que l'approche par simulation physique présente un intérêt et une importance tout particuliers. Une telle simulation permet, à l'échelle physique et temporel du laboratoire, de représenter ce qui se passe dans la nature pour des dimensions et des durées inaccessibles directement.

A l'origine des dômes de sel, on trouve une séquence (anormale vis-à-vis de l'équilibre dans le champ de gravité), composée d'une couche de roche "lourde" placée au-dessus d'une couche de roche «légère». Un retour à l'équilibre peut a priori se concevoir de deux manières :

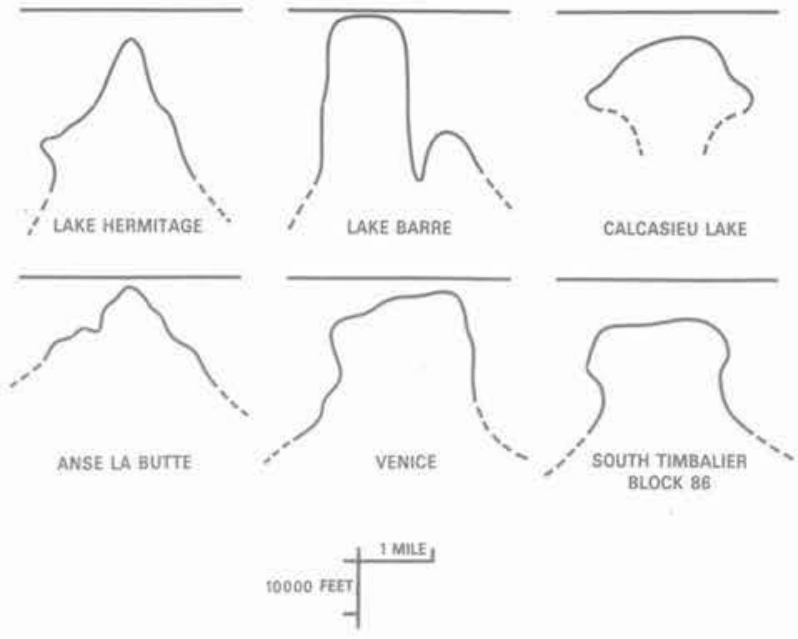

\section{Fig. 1. - Coupes de six dómes du GULF (d'après MURRAY).}

Fig. 1. - Vertical sections through six Gulf domes (after MURRAY).

- une inversion qui conduit, in fine, le sel à surmonter la roche plus lourde:

- un mélange des deux matériaux conduisant à une couche unique relativement homogène.

La genèse de la catastrophe exige que les matériaux soient très proches du comportement fluide, autrement dit : bien au-delà des limites élastiques, tandis que les contraintes sont très faibles par rapport à ces limites telles qu'on les observe dans les essais de laboratoire. Donc, un changement de l'échelle du temps modifie complètement les matériaux.

Sur plusieurs points, notamment pour ce qui concerne la sécurité, le comportement solide est très différent du comportement fluide.

Pour les fluides, une instabilité est engendrée dès que la force motrice apparaît. Elle se développe selon exp $(\mathrm{t} / \tau) \quad(\tau=$ temps caractéristique $)$, et ne s'arrête que quand l'ordre géostatique redevient stable.

Les présents essais ont montré l'existence de cas stables. Dans certains cas instables, une séquence d'évolution très lente est suivie d'une catastrophe très brusque, et, par la suite, d'une seconde période d'évolution très lente. Parfois, l'évolution s'arrête complètement.

Si l'hypothèse du comportement fluide est admise, on n'a pas besoin d'une centrifugeuse. Des modèles réduits "sur table » existent abondamment. Par contre, l'hypothèse d'un comportement "solide» exige une centrifugeuse.

BUCKY [2] a été le premier à utiliser une centrifugeuse pour résoudre des problèmes miniers, donc à l'échelle du temps "humain". Un grand nombre de $\mathrm{g}$ a été nécessaire car les maquettes utilisaient la même roche qu'in situ. BUCKY a étudié les contraintes par des modèles réduits photoélastiques centrifugés [3]. 
De petites centrifugeuses ont été utilisées notamment par RAMBERG [4] pour des cas géostatiques.

Le choix de matériaux a été dicté par la commodité de la fabrication des modèles. La centrifugeuse a été utilisée avec un nombre de $\mathrm{g}$ de l'ordre de mille, afin d'obtenir un comportement fluide.

Ces essais ont donné des formes similaires à celles des essais * sur table» de DOBRIN [5] et de NETTLETON [6]. Ce dernier a été le pionnier dans l'emploi de ces types de modèles « fluides $»$. Tous ces modèles étaient de très petites dimensions, de quelques centimètres seulement. Les modèles de DOBRIN et NETTLETON avaient un certain avantage sur ceux de RAMBERG : s'agissant de modèles «sur table», l'observation de l'évolution est aisée même sur de longues durées.

Étant donné que le matériau réel est remplacé par un solide très peu résistant, un grand nombre de g n'est pas nécessaire. Une gamme de $10-100 \mathrm{~g}$ est suffisante.

La taille de la centrifugeuse est très importante. Cette taille permet d'observer le modèle en permanence pendant des heures et des jours, d'enregistrer l'ensemble des phénomènes sur vidéocassette, de tenir compte de petits détails géométriques, d'éviter les effets de bord, "d'embarquer " des systèmes de mesures tels que ceux utilisant la photoélasticité, et d'introduire divers capteurs. Toutes ces informations, notamment les vidéocassettes, constituent pour le chercheur une représentation complète, bien que synthétique d'un phénomène géostatique ; un film de synthèse a été réalisé par le Service audiovisuel de l'École Polytechnique.

\section{PROBLÈMES DE SIMILITUDE}

(On utilise la notation de J. MANDEL : l'échelle est le rapport d'une dimension du modèle sur la dimension caractéristique correspondante du prototype: $A$ (modèle) $/ A$ (prototype) $\equiv A_{m} / A \equiv A^{*}$ ).

Pour expliquer les essais de NETTLETON, HUBBERT [7] en 1937 a écrit un article consacré aux problèmes de similitude en géologie. Il fonde son analyse sur celle de GALILÉE, faite 300 ans auparavant [8].

HUBBERT cite une partie du résumé de GALILÊE :

"From what has already been demonstrated, you can plainly see the impossibility of increasing the size of structures to vast dimensions either in art or in nature; likewise the impossibility of building ships, palaces, or temples of enormous size in such a way that their oars, yards, beams, iron-bolts, and, in short, all their other parts will hold together; nor can nature produce trees of extraordinary size because the branches would break down under their own weight; so also it would be impossible to build up the bony structures of men, horses, or other animals so as to hold together and perform their normal functions if these animals were to be increased enormously in height; for this increase in height can be accomplished only by employing a material which is harder and stronger than usual, or by enlarging the size of the bones, thus changing their shape until the form and appearance of the animals suggest a monstrosity..

"... Clearly then if one wishes to maintain in a great giant the same proportion of limb as that found in an ordinary man he must either find a harder and stronger material for making the bones, or he must admit a diminution of strength in comparison with men of medium stature; for if his height be increased inordinately he will fall and be crushed under his own weight. Whereas, if the size of a body be diminished, the strength of that body is not diminished in the same proportion; indeed the smaller the body the greater its relative strength. Thus a small dog could probably carry on his back two or three dogs of his own size; but 1 believe that a horse could not carry even one of his own size."

Selon GALILÉE : $\sigma^{*}=\rho^{*} \mathrm{~g}^{*} \ell^{*}$ et $\mathrm{C}^{*}=\sigma^{*}$ puisqu'il parle de la résistance $(C=$ Cohésion ; $\sigma=$ contrainte ; $\rho=$ masse volumique $; g=$ accélération de la pesanteur: $l=$ longueur) .

HUBBERT reprend ces relations en ajoutant $t^{*}=$ $\eta^{*} / \sigma^{*}(\eta=$ coefficient de viscosité). Il définit la procédure suivante : $\ell_{m}$ est tout simplement la hauteur du modèle. $l$ est la hauteur des couches géologiques prises en compte; $t_{m}$ est l'intervalle de temps qui sépare le début et la fin de l'évolution. $t$ « in situ » est la période géologique correspondante. $\eta$ est prise comme une constante qui ne dépend pas de l'échelle du temps, et qu'on peut déterminer par des essais en laboratoire. Il vient :

$$
\mathrm{t}^{*}=\eta^{*} /\left(\rho^{*} \mathrm{~g}^{*} /{ }^{*}\right)
$$

De plus, $C^{*}$ doit être égale à $\sigma^{*}$. C, dans cette relation. est le seuil plastique qui, selon HUBBERT (p. 1484), ne dépend pas de la vitesse de déformation.

DOBRIN [5] a entrepris de vérifier l'analyse de HUBBERT. Il écrit dans son résumé :

"Over long periods of time salt dome form by a process of flow comparable to that of highly viscous liquids in the manner suggested by ARRHENIUS NADAI and in more details by NETTLETON."

Sa formule (1) est : $\eta^{*}=\rho^{*} \mathrm{~g}^{*} l^{*} \mathrm{t}^{*}$, en plus $C=0$; DOBRIN n'utilise que des fluides dans ses modèles. Il résume la forme de ses résultats dans sa figure 10 (figure 2), où, chose curieuse, $\rho^{\circ}$ est remplacé par $\Delta \rho^{*}$; sur la partie linéaire, c'est $\Delta Z^{*}$ qui importe et semble assez indépendant de la hauteur du modèle.

Une courbe typique des essais avec des solides est superposée, en pointillés, sur la figure 2. Si c'est le cas in situ, la période de croissance rapide $\Delta t$ est petite par rapport à la période totale. La relation $\eta=\Delta \rho \mathrm{g} \Delta \mathrm{Z} \Delta \mathrm{t}$ utilisée pour trouver une valeur pour $\eta$ in situ risque donc d'être très différente de $\eta=\Delta \rho \mathrm{g} \mathrm{Z} \mathrm{t}$, prise par DOBRIN et tous les autres chercheurs jusqu'à présent comme base de validation. Assez souvent, des solides (comme la pâte à modeler) ont été utilisés mais sans tenir compte de la relation $C^{*}=\sigma^{*}$. 


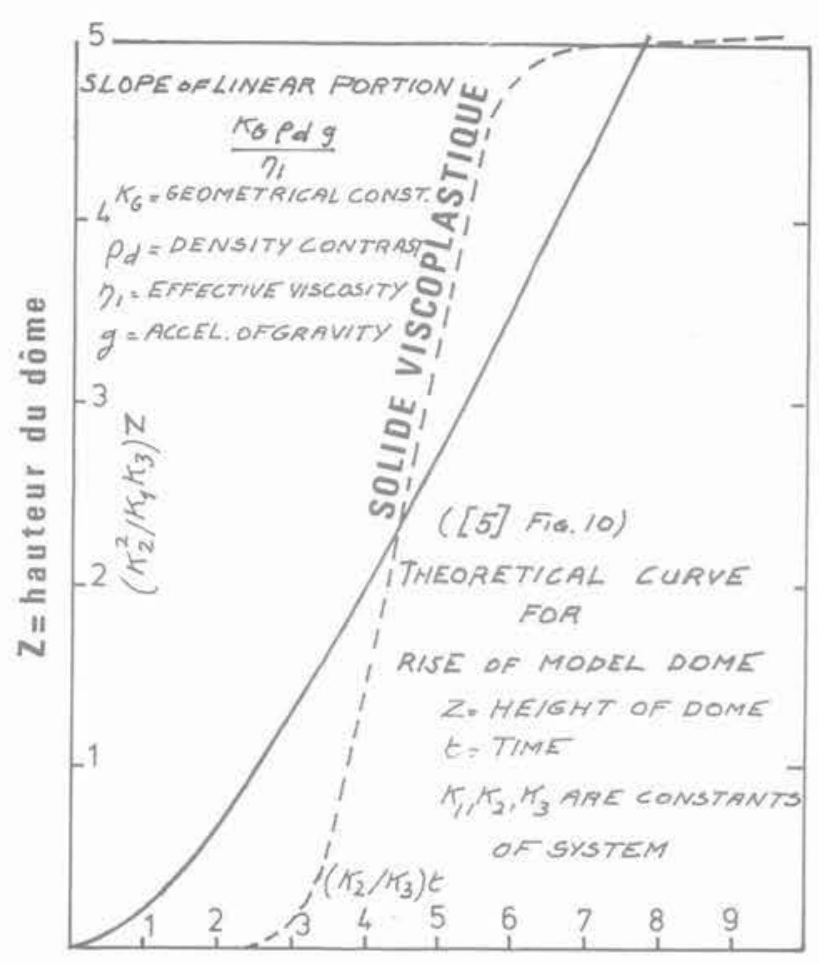

Fig. 2. - La montée d'un dóme de sel (d'après DOBRIN, [5], fig. 10). Fig. 2. - Rise of model dome (after DOBRIN, [5], fig. 10).

Méthodes anciennes :

Il faut revenir plus en arrière dans le temps pour trouver un autre point de vue. Le géologue LEES [9] qui a étudié les dômes de sel en Iran, Égypte et Israël écrit en 1931 :

"The Persian salt domes present some unique evidence on the plasticity problem. In the case of several of the higher domes the salt has commenced to flow downhill as a salt-glacier. The rock remains solid with its normal banded structure...".

et plus loin :

"If the forces necessary to make salt plastic is of the order of one hundredth of that indicated by laboratory experiments, our conceptions of the problem are entierely changed."

LEES dans sa figure 6 (figure 3) présente le modèle de F. RINNE pour expliquer l'écoulement du sel. Ce modèle a été repris par GUSSOW (figure 5 de [10] figure 4) en 1968. Or, on trouve ce modèle (physique cette fois) dans l'ouvrage de A. DAUBREE [11] de 1879 , et qui présente les travaux d'une trentaine d'années. On arrive donc en 1850.

DAUBRÉE parle d'un jet d'argile dans sa figure 141 (figure 5) et son appareil a été utilisé pour étudier les bandes dans le jet - signe d'écoulement plastique solide - . Cet appareil a souvent été utilisé pour simuler les dômes de sel entre 1920 et 1930, mais les résultats obtenus étaient décevants.

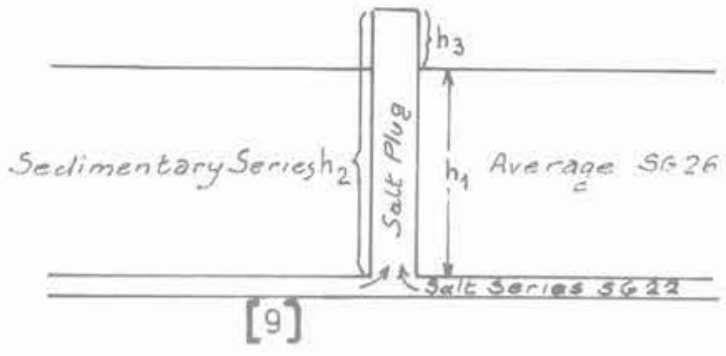

Fig. 3. - Le schéma d'équilibre du dôme (d'après LEES).

Fig. 3. - The dome's equilibrium scheme (presented by LEES).

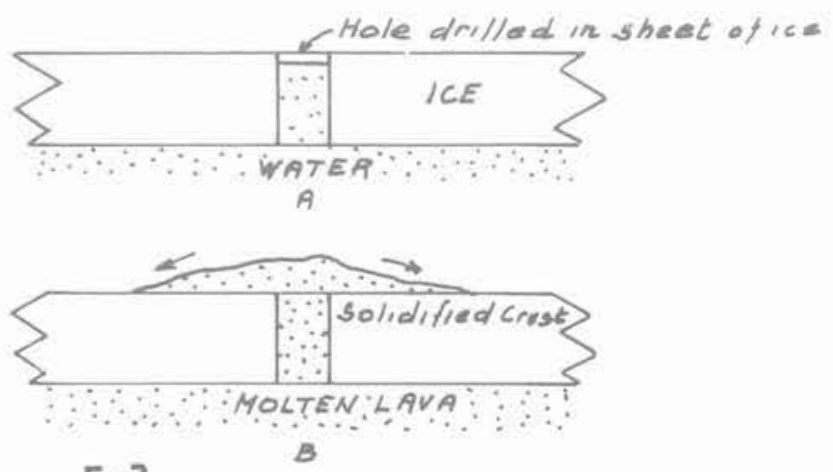

[10]

Fig. 4. - Les schémas d'équilibre (d'après GUSSOW).

Fig. 4. - The equilibrium schemes (after GUSSOW).

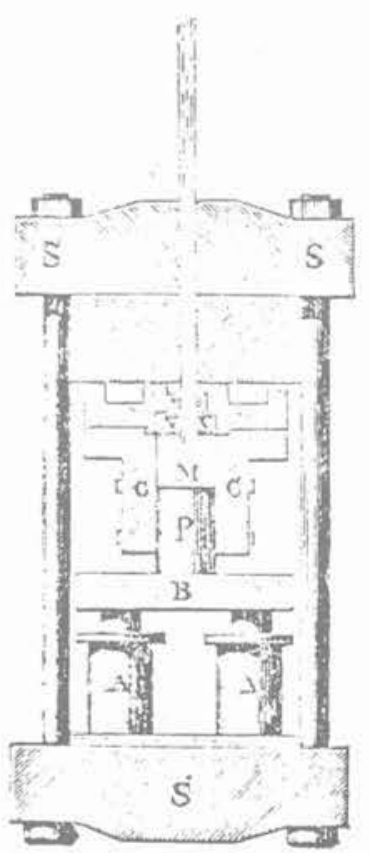

Fig. 5. - L'appareil de DAUBRÉE. Fig. 5. - DAUBREE's apparatus. 


\section{Selon LEES [9] :}

"Experimental work in connection with the plasticity of salt is less satisfactory when the results are applied to practical problems. In such experiments the importance of the time factor has not been considered sufficiently. Test maintained through hours and even days are not comparable with geological processes deadling in years or many thousands of years."

Dans les systèmes comme l'appareil DAUBRÉE, c'est la résistance du « sel » qui compte et non pas celle de la matrice, supposée rigide, La forme du jet est celle d'une colonne.

La bible mentionne au sujet du Mont Sodome : "La femme de LOTH regarda en arrière et devint une colonne de sel». La seule colonne de sel dans cette région est la montagne elle-même, considérée comme un dôme de sel par LEES, en 1922 [9]. Selon lui : "The latest movement of the salt is post dilubium and, therefore, falls withing, perhaps, historic times, and it is interesting to speculate whether the story of Sodom and Gomorrah may not have been in some way connected with the movement of the salt dome." Si la réponse est positive, c'est un exemple de croissance rapide (même catastrophique) entre deux périodes quasiment stables (un comportement selon la ligne pointillée de la figure 2). La colonne de la femme de LOTH est longue de $10 \mathrm{~km}$ et large de $1,5 \mathrm{~km}$; son rayon hydraulique est de $r=30 / 23=1,3 \mathrm{~km}$. La cohésion maximale du sel, qui interdit l'écoulement pour une colonne infinie, est $C_{\max }=\Delta p g$ $\mathrm{r} / 2=1,3 \mathrm{MPa}$.

Le cas des glaciers de sel, mentionné par LEES, peut servir pour un calcul similaire. L'équilibre statiquement admissible d'une pente infinie d'inclinaison $\alpha$. La formule est $\mathrm{C}=(\mathrm{g} \mathrm{g} \sin 2 \alpha) / 2$, h est l'épaisseur de la couche de sel. Pour une pente de $1 / 3, \mathrm{~h}=100 \mathrm{~m}$. $p=2,2 \mathrm{t} / \mathrm{m}^{3} ;$ on obtient $\mathrm{c}_{\max }=0,66 \mathrm{MPa}$. Ces calculs très approchés donnent quand même un ordre de grandeur d'une cohésion à l'échelle géologique. Elle est beaucoup plus petite que les valeurs trouvées en laboratoire, mais elle est suffisante pour empêcher le phénomène dans bien des cas.

Le fait que des dômes et des diapirs n'existent pas toujours est le meilleur support de l'hypothèse que les roches et le sel en particulier sont des solides, même à l'échelle géologique.

\section{Les échelles :}

L'échelle de contrainte est prise comme $C^{*}$ ( $C$ in situ doit être estimée).

L'échelle $\Delta \rho^{*}$ est déduite des masses volumiques in situ.

L'échelle de longueur $/$ * est donnée seulement dans le cas où est présente une irrégularité de l'interface. Alors, l'échelle de g pour le phénomène «réel » sera. donnée par:

$$
\Delta \rho^{*} \mathrm{~g}^{*} l^{*}=\mathrm{C}^{*} \text {. }
$$

Notamment, pour une interface plane l'échelle $l^{*}$ est mal définie. Or, comme les échelles sont assez floues, une variation de $\mathrm{g}^{*}$ par la centrifugeuse permet d'exécuter un nombre d'essais qui sont voisins du cas réel, et d'en déduire des conclusions relatives à la sécurité par exemple.

Pour déterminer l'échelle du temps par $\mathrm{t}^{*}=\eta^{*} / \mathrm{C}^{*}$, il faut estimer $\eta$ in situ, ce qui n'est pas facile. Il n'y a pas de raison que les valeurs trouvées en laboratoire soient adéquates. Les estimations in situ exigent une définition de la période de croissance, plus une estimation du champ des contraintes, afin d'en déduire la résistance visqueuse. Le temps caractéristique $\tau$ est donné par la formule $\tau=\eta /(\mathrm{g} l-\alpha \mathrm{C})$ ( $\alpha$ est une constante qui dépend de la géométrie : / est une longeur typique du diapir).

\section{LES CALCULS ANALYTIQUES}

Ces calculs sont possibles dans le cas d'un comportement fluide pour lequel les équations sont linéarisées et les interfaces sont planes. On cherche une longueur typique $\ell$. L'évolution dans le temps est prise en compte par une séparation selon HELMHOLTZ. La fonction temporelle est exp $(t / \tau)$, $\tau$ est un temps caractéristique. A priori, les résultats sont valables pour des hauteurs de dômes allant jusque $\simeq \ell / 10$. Après cette hauteur, il faut tenir compte de la nouvelle forme de l'interface. Historiquement, il faut évoquer d'abord l'étude de G. TAYLOR, faite 20 ans après les essais de NETTLETON, et 25 ans après ses propres études sur l'instabilité de l'écoulement d'un fluide visqueux entre deux cylindres.

Les équations du problème sont linéaires, de sorte qu'une forme sinusoïdale peut être choisie pour l'irrégularité : on note $\lambda$ la longueur d'onde de l'irrégularité. Il n'y a pas d'autre longueur qui intervienne dans le problème, si les hauteurs des couches sont supposées illimitées. Les masses volumiques sont $p$ pour le matériau surincombant et $\rho$ pour le matériau initialement inférieur; les fluides sont soumis à une accélération $\mathrm{g}$, de sorte que la force volumique motrice est $\Delta \gamma=\mathrm{g} 6$ - p). TAYLOR a établi que l'irrégularité croît selon exp $(\mathrm{t} / \tau)$, où le temps caractéristique $\tau$ est donné par la formule de GALILEE. En effet, sil'on pose comme quantité homogène à une accélération $A=\Delta \gamma /\langle\rho\rangle$ avec $\langle p\rangle=(p+\bar{p}) / 2$, l'expression de TAYLOR, soit $\tau=\sqrt{\langle\rho\rangle \lambda /(\Delta \gamma \pi)}$ devient $\tau=\sqrt{\lambda /(A \pi)}$. Or la formule de GALILEE est un exemple classique d'utilisation de l'analyse dimensionnelle, dans laquelle une seule variable sans dimension existe, soit $\frac{A t^{2}}{\lambda}$, de sorte que cette quantité est constante. TAYLOR souligne que son calcul n'est valable que pour les déplacements qui demeurent faible vis-à-vis de la longueur d'onde $\lambda$, ce qui explique le paradoxe suivant : plus $\lambda$ est petit, plus la croissance est rapide. Pour une couche d'épaisseur $h$, il est logique de prendre $\tau \cong \sqrt{\langle<\rangle h / \Delta \gamma}$. Pour des roches, on peut retenir $\langle p\rangle / \Delta \gamma \cong$ $2 \mathrm{~s}^{2} / \mathrm{m}$ donc $\tau \cong \sqrt{2 \mathrm{~h}}$ en secondes. 
Cette montée « explosive » a pour origine la conversion complète de l'énergie potentielle du champ de pesanteur en énergie cinétique. Une image plus réaliste du mouvement exige l'introduction de lois de comportement qui tiennent compte de la dissipation d'une partie de l'énergie potentielle dégagée. En même temps, il ne faut pas totalement écarter la possibilité qu'une certaine partie de l'énergie potentielle reste disponible pour une conversion en énergie cinétique, autorisant une catastrophe de type $\alpha$ TAYLOR».

$$
\begin{aligned}
& \text { La relation } \sigma=\eta \mathrm{d} \varepsilon / \mathrm{dt} \text { avec } \\
& \qquad \varepsilon=\varepsilon(\mathrm{x}) \exp (\mathrm{t} / \tau)
\end{aligned}
$$

est réduite à :

$$
\sigma(\mathrm{x})=(\eta / \tau) \varepsilon(\mathrm{x}) .
$$

L'étude de l'instabilité pour un fluide visqueux est inspirée du cas du flambage d'une poutre élastique (problème d'EULER).

Si la longueur de la poutre est $\ell$, la hauteur h et la largeur 1, l'équation pour le déplacement w est :

$$
\left.\mathrm{d}^{2} w / d x^{2}+\sigma_{\max } w /(\eta / \tau)\left(h^{2} / \sigma\right)\right)=0 .
$$

La valeur critique de $\sigma_{\max }$, soit $\sigma_{a}$ est alors :

$$
\sigma_{c r}=\alpha(\mathrm{h} / \ell)^{2}(\eta / \tau) \text {. }
$$

$\sigma_{c}$ est une fonction de $\Delta y$ et de la géométrie, de sorte que

$$
\tau=\left(1 / /^{2}\right) f(\Delta \gamma, h, \eta) \text {. }
$$

Pour $\ell \rightarrow \infty: \tau \rightarrow 0$.

Pour $\ell \rightarrow \infty$, le comportement est de type TAYLOR, et pour $l \rightarrow 0$ de type EULER, et selon le théorème de ROLLE, appliqué à la fontion $1 / \tau$ fonction de $l$, il se trouve des longueurs $l_{1}, l_{2} \ldots$ pour lesquels $1 / \tau$ est maximal. Dans certains cas, il y a un minimum très prononcé de $\tau$.

La longueur / correspondante est $\lambda / 2$, moitié de la longueur d'onde de la perturbation sinusoïdale qui va crốtre au détriment des autres. Pour ces cas, l'échelle des longueurs, est égale à $\lambda^{*}$. par contre, dans le cas où le minimum est plat, où il $y$ a plusieurs minimums de valeurs assez similaires, l'échelle des longueurs n'est pas définie, ce qui entraîne la non-définition des échelles des contraintes et du temps.

En résumé, dans les modèles flutdes une définition floue de la longueur caractéristique se transmet à la définition des échelles. NETTLETON et d'autres chercheurs ont initialisé leurs essais par une aspérité géométrique prononcée.

\section{L'histoire des contraintes :}

Dans les essais centrifugés, la force motrice $\Delta p_{m} g_{m}$ est appliquée d'une façon discontinue. L'histoire des contraintes qui s'ensuit ne correspond pas au cas in situ, surtout quand on cherche à étudier l'évolution d'un dôme déjà établi.

C'est pourquoi le nombre de g est augmenté très lentement. Normalement, un compromis est trouvé, compte tenu du coût de l'heure de centrifugation.

\section{MATÉRIAUX}

Le choix des matériaux est gouverné par deux sortes de considérations :

a) la disponibilité, le coût et la facilité de préparation; b) les besoins de la similitude et de la mesure.

Le premier ensemble de facteurs est très important. On doit garder à l'esprit que les essais conduisent à la destruction d'un grand nombre de modèles réduits, de taille substantielle. Si le souci de disposer des meilleurs matériaux possibles conduit à choisir des matériaux coûteux, et donc à réduire le nombre d'essais, on court le risque de tomber dans le piège des « résultats rares ». Ne disposant, en raison de leur coût, que d'un nombre très limitê de résultats, le chercheur développe à leur égard un respect tout à fait démesuré, qui pousse à tenter de les interpréter à * tout prix *. Au contraire, dans un travail de recherche, surtout expérimental, il faut être prêt à rejeter une partie des résultats. Pour cette raison. les modeles utilisent des argiles et de la gélatine pour les zones étudiées en photoélasticité.

Un appareil DAUBRÉE, dans lequel la pression a été exercée pneumatiquement, a servi de rhéomètre. On fait s'écouler les matériaux dans un tube transparent. La valeur de la pression motrice et la vitesse d'écoulement ont servi pour définir $C$ et $\eta$ pour un matériau de BINGHAM, selon une formule de POISEUILLE modifiée. Les mélanges suivants ont été utilisés.

1. Argile de Provins "grise " : $100 \mathrm{~g}$ d'argile, $100 \mathrm{~g}$ d'eau, $100 \mathrm{~g}$ de corindon :

Masse volumique $\rho=1,86 \mathrm{~g} / \mathrm{cm}^{3}$

Cohésion $\mathrm{C}=0.5 \mathrm{kPa}$

Viscosité $\eta=7000$ Pa.s.

2. Argile "blanche" (kaolin) : $100 \mathrm{~g}$ d'argile, $80 \mathrm{~g}$ d'eau (correspondant à la limite de liquidité) :

Masse volumique $p=1,54 \mathrm{~g} / \mathrm{cm}^{3}$

Cohésion $\mathrm{C}=0.4 \mathrm{kPa}$

Viscosité $=\eta=10000 \mathrm{~Pa} . \mathrm{s}$

\section{Gélatine :}

Masse volumique $\rho=1.31 \mathrm{~g} / \mathrm{cm}^{3}$

Cohésion $\mathrm{C}=0,6 \mathrm{kPa}$

Viscosité $\eta=10000 \mathrm{~Pa} . \mathrm{s}$

Photoélasticité $0.8 \mathrm{kPa}$ par frange

( $C$ variant de 2 à 2,5 franges dans les essais de poutre).

4. Argile ablanche» affaiblie: argile $100 \mathrm{~g}$, eau $120 \mathrm{~g}$ :

Masse volumique $\rho=1,40 \mathrm{~g} / \mathrm{cm}^{3}$

Cohésion $\mathrm{C}=0,05 \mathrm{kPa}$

Viscosité $\eta=2000 \mathrm{~Pa}$.s

5. Argile "grise» durcie : argile $100 \mathrm{~g}$, eau $60 \mathrm{~g}$, corindon $80 \mathrm{~g}$ :

Masse volumique $p=2,05 \mathrm{~g} / \mathrm{cm}^{3}$

Cohésion $\mathrm{C}=5 \mathrm{kPa}$

Viscosité $=\eta=20000$ Pa.s 


\section{Remarque :}

La gélatine, seul matériau disponible en photoélasticité, est très fragile, d'où une dispersion considérable de la valeur de C. Le mélange $n^{\circ} 3$ est à la limite de la sensibilité photoélastique.

Les systèmes géologiques suivants ont été utilisés principalement :

1. Couche supérieure en argile grise chargée (mélange $n^{\circ} 1$ ). Couche inférieure d'argile blanche non chargée (mélange $n^{\circ} 2$ ). Pour ce couple :

$\Delta p=0,32 \mathrm{~g} / \mathrm{cm}^{3} \quad\langle p\rangle=1,7 \mathrm{~g} / \mathrm{cm}^{3}$

$\Delta \rho /\left\langle_{\rho}\right\rangle=0,19$.

2. Couche supérieure en argile grise chargée (mélange $n^{\circ} 1$ ). Couche inférieure en gélatine (mélange $n^{\circ} 3$ ). Pour ce couple :

$\Delta p=0,56 \mathrm{~g} / \mathrm{cm}^{3} \quad\langle p\rangle=1,58 \mathrm{~g} / \mathrm{cm}^{3}$

$\Delta \rho /<\rho>0=0.35$.

3. Couche supérieure en argile grise chargée (mélange $\left.n^{\circ} 1\right)$. Couche inférieure en argile blanche non chargée (mélange $n^{\circ} 2$ ) comprenant une inclusion moins résistante représentant les déchets (mélange $\left.n^{\circ} 4\right)$.

4. Couche supérieure en argile grise chargée (mélange $n^{\circ} 1$ ) renforcée par une couche mince d'argile grise durcie (mélange $n^{\circ} 5$ ).

\section{LES INSTALLATIONS}

Il est évident que dans un premier temps il était nécessaire de tirer le maximum d'informations des modèles à deux dimensions, avec l'objectif de ne passer qu'ensuite aux modèles à trois dimensions.

Les modèles à trois dimensions ne permettent pas de suivre l'évolution du phénomène puisque les matériaux sont opaques. D'autre part, la durée d'un essai est nécessairement plus longue et donc le coût est supérieur.

Une tranche des couches géologiques est maintenue entre deux plaques de plexiglass, ce qui permet de voir, éclairés de face, les systèmes argile-argile et, éclairés par derrière en transparence, les zones photoélastiques en gélatine.

A $100 \mathrm{~g}$ et pour $\langle p\rangle=1,6 \mathrm{~g} / \mathrm{cm}^{3}$ la pression à $0,4 \mathrm{~m}$ de profondeur dans le modèle est $0,64 \mathrm{MPa}$. Afin de conserver un coût raisonnable, la cellule contenant les matériaux est conçue comme suit : la cellule principale est munie d'une fenêtre de largeur $0,2 \mathrm{~m}$ (sur toute la hauteur) en plexiglas de $5 \mathrm{~cm}$ d'épaisseur. Le reste de la largeur est protégée par deux plaques d'acier de $2 \mathrm{~cm}$ d'épaisseur, trouée de manière régulière. Ces trous permettent une inspection de contrôle. La largeur nette de l'échantillon est de $0,9 \mathrm{~m}$ de la hauteur de $0,45 \mathrm{~m}$ (plus une bordure de $5 \mathrm{~cm}$ ). Cette cellule occupe toute la largeur disponible de la nacelle pivotante de la centrifugeuse. Pour mettre en œuvre la photoélasticité, on applique deux plaques polarisantes sur les fenêtres et on éclaire par l'arrière au moyen de huit ampoules capables de résister à une accélération de $100 \mathrm{~g}$. Le modèle est également éclairé par devant au moyen d'une ampoule du même type. Un miroir renvoie l'image à la caméra-vidéo fixée sur le bras de la centrifugeuse à $1.5 \mathrm{~m}$ de la cellule. L'image transmise est d'une qualité correcte, Le déroulement de l'essai est enregistré en temps-modèle réel, à raison de vingt-cinq images par seconde.
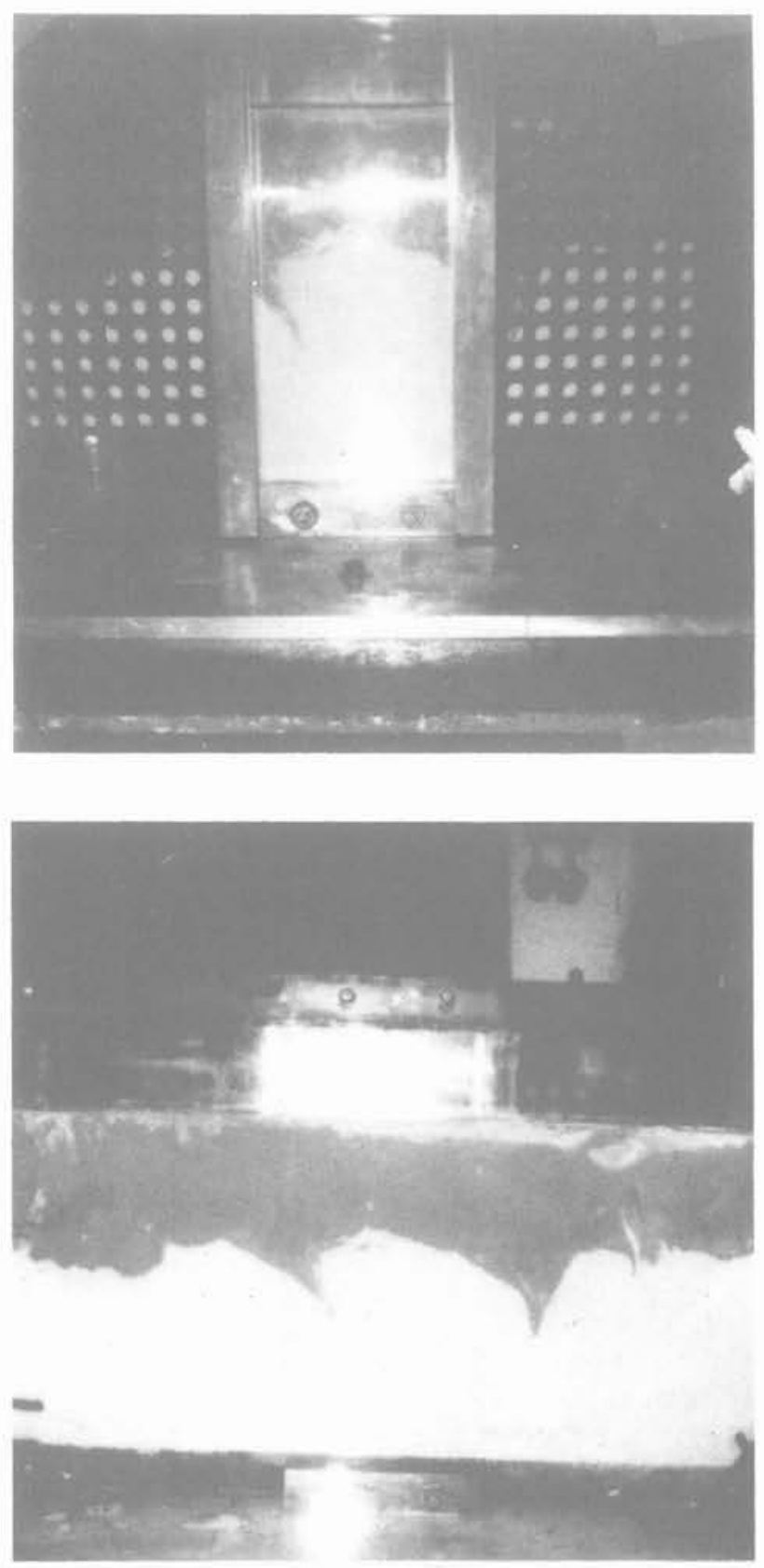

Fig. 6. - a) La cellule avec plaques d'acier. b) Les plaques d'acier enlevées. Fig. 6. - a) The cell equipped with protective steel plates.

b) The protective plates removed. 
Un appareil vidéo spécial permet de ralentir la cadence de projection jusqu'à la cadence image par image.

Deux cellules secondaires ont été construites. Elles ont la même hauteur, et une largeur nette de $0,4 \mathrm{~m}$. Les plaques en plexiglas sont complètement couvertes par les plaques en acier trouées. Elles sont utilisées ensemble, de sorte qu'on exécute deux essais à la fois. $\mathrm{Ce}$ système ne contient pas de miroir. La centrifugation est arrêtée périodiquement et les cellules inspectées. En cas de besoin. les plaques sont démontées et des photos sont prises.

\section{L'essai DAUBRÉE}

Une de ces cellules est munie d'une traverse trouée qui permet d'exécuter des essais de jets sous une presse en laboratoire. La presse écrase la couche inférieure qui forme un jet viscoplastique dans la couche supérieure. C'est un essai presque sans similitude, mais qui est utile pour observer certains phénomènes, notamment les lignes de LUDERS et la fissuration.

\section{LES RÉSULTATS}

Un certain nombre de modèles ont été * stables * c'està-dire qu'une centrifugation à $100 \mathrm{~g}$ pendant des heures n'a rien modifié au modèle.

On s'intéresse ici surtout aux cas instables. Les coefficients de sécurité sont estimés en prenant comme étalon le cas d'un cylindre flottant dans le sol c'est-à-dire : le problème de STOKES en viscoplasticité. On doit comparer les forces motrices d'un cas donné par rapport au cas étalon.

Les séries géologiques et les configurations géométriques ont été choisies pour étudier l'initialisation. Tatténuation et l'accélération de la croissance diapirique. C'est surtout ces aspects qui sont discutés ici. Notamment les scénarios qui ont été simulés peuvent bien exister avec un coefficient de sécurité égal à 1, surtout en grande profondeur. Ainsi, les essais pourraient expliquer les évolutions de ces catastrophes géologiques.

\subsection{Le problème de STOKES}

Une sphère rigide de masse spécifique donnée est placée dans un milieu infini composé d'un matériau de $\operatorname{BINGHAM}(\mathrm{C}, \eta)$, et de masse spécifique plus élevée que celle de la sphère (le rayon est $\mathrm{R}$. l'écart de densités $\Delta \rho)$. Pour $\Delta \rho g$ assez faible, la sphère reste immobile. Le seuil d'apparition du mouvement dépend uniquement de $C$ et peut être estimé par des calculs de charge limite de la théorie de plasticité. On considère d'abord un disque de rayon $R$, ou plutôt une plaque pour le cas bidimensionnel. En avant et en arrière de la plaque on suppose des zones de RANKIN. La direction de la pression maximale a tourné de $3 \pi / 2$ entre ces deux zones. la charge critique $\mathrm{F} / \mathrm{A} \equiv \sigma_{n}(\mathrm{~A}=$ aire de la section droite) est donnée par $\sigma_{a}=(3 \pi+2) \mathrm{C}$. Pour une sphère ou un cylindre. il faut ajouter la résistance

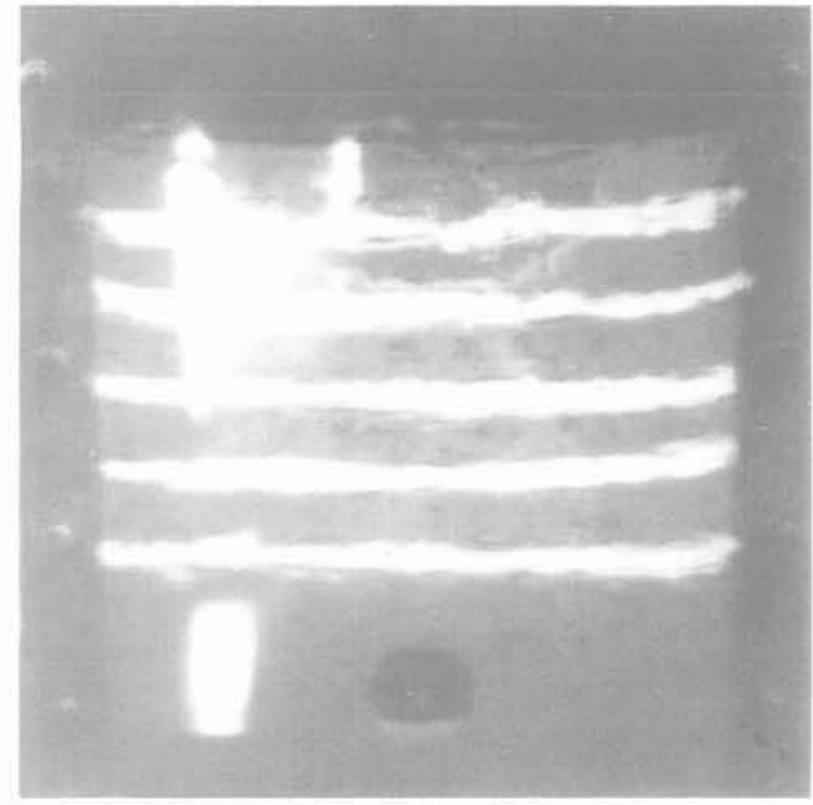

a)

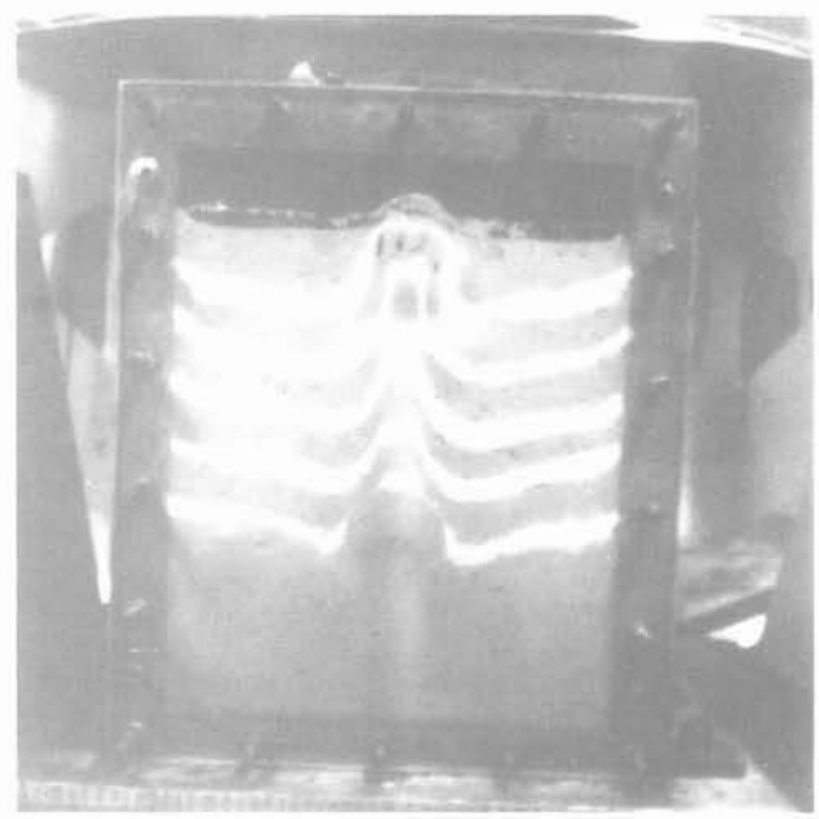

b)

Fig. 7. - Le problème de STOKES viscoplastique : a) Configuration initiale.

b) Configuration finale, la surface libre est atteinte.

Fig. 7. - STOKES' viscoplastic problem : a) Initial configuration. b) Final configuration. 

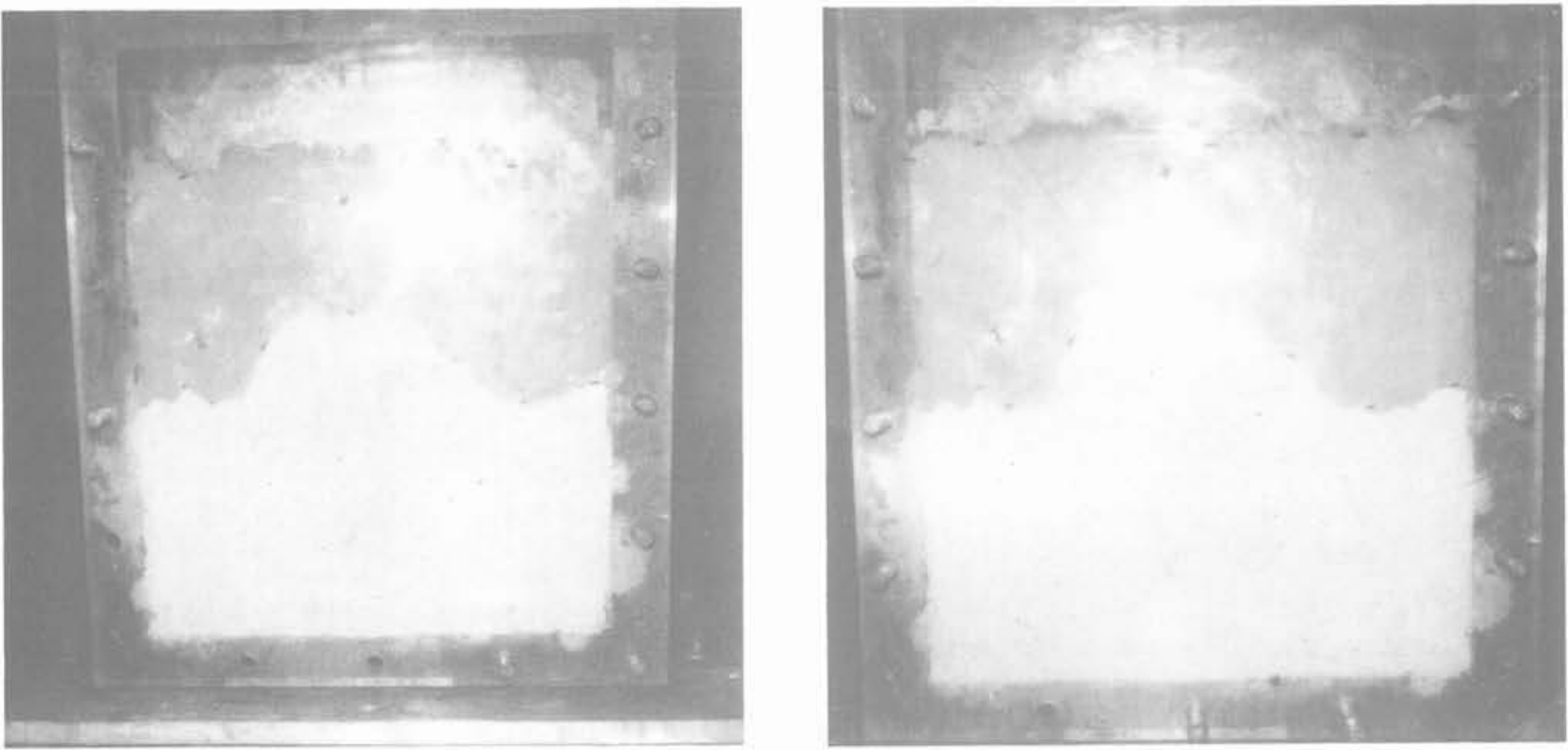

a) $30 \mathrm{~g}$

b) $60 \mathrm{~g}$
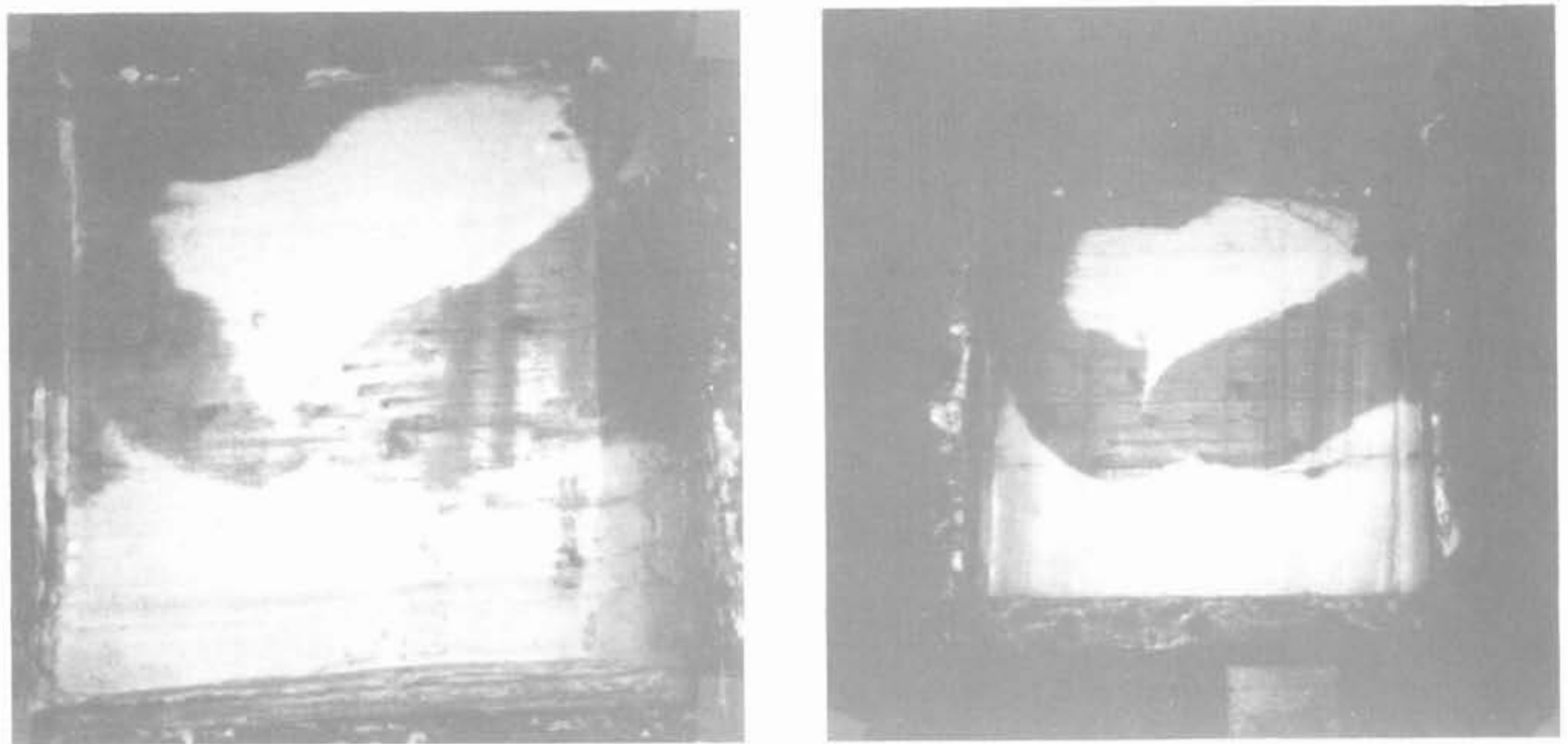

c) $60 \mathrm{~g}^{\prime} \rightarrow 100 \mathrm{~g}^{\prime}$

Fig. 8. - Petite cellule - Système 1:

$\left.d^{\prime}\right) 60 g^{\prime} \rightarrow 100 g$

\section{a) Milieu de la cellule.}

b) Près du plexiglass.

Fig. 8. - Small cell - System 1:

a) Middle of the cell.

b) Near the plexiglass.

due aux parois latérales, d'où : $\sigma_{c} \cong(3 \pi+4)$ $\mathrm{C}=13,4 \mathrm{C}$

Un cylindre de diamètre $8 \mathrm{~cm}$ a été placé dans le mélange 1: $\Delta \rho=1,4 \mathrm{~g} / \mathrm{cm}^{3}$.

A $12 \mathrm{~g}$, le mouvement est imperceptible après une heure de centrifugation. Ceci correspond à
$\mathrm{C}=800 \mathrm{~Pa}$ (la valeur donnée par l'appareil DAUBRÉE est de $500 \mathrm{~Pa}$ ). Le calcul par un champ statiquement admissible donne une majoration pour $\mathrm{C}$.

Au-delà de 12 g', on peut prendre la formule de STOKES comme une estimation pour la vitesse de flottaison à la surface, prenant comme force motrice $\Delta \rho \Delta \mathrm{g}$ $\left(\Delta g^{\prime}=g^{\prime}-12\right)$ (la notation $g^{\prime}$ est utilisée pour le nombre de g, afin de distinguer de "gramme»). 
$\mathrm{F} /\left(\pi \mathrm{R}^{2}\right)=\sigma=6 \eta \mathrm{v} / \mathrm{R}$.

$\mathrm{F}=\Delta \rho \Delta \mathrm{g} 4 \pi \mathrm{R}^{3} / 3$

L'enregistrement vidéo pour $16 \mathrm{~g}$ ' donne : $\eta \cong 20000$ Pa.s.

La figure 7 montre les configurations initiale et finale pour un essai dans la petite cellule. Les deux essais ont donné pratiquement les mêmes résultats. A quoi correspond cet essai?

Dans la figure $8 \mathrm{c}$, on voit un dôme de sel flottant dans la couverture. Le mouvement de la couverture autour du dôme est similaire à celui indiqué par les bandes dans la figure $7 b$.

Les bulles ont été utilisées pour mesurer la charge de l'électron, et à cet effet HADAMARD (1911) [13] a étudié le mouvement d'une sphère visqueuse dans un fluide visqueux. HADAMARD a montré que la sphère garde sa forme, et que la vitesse moyenne est très peu dépendante de la viscosité de la sphère.

La figure 9, qui est la figure 1 dans l'article de DAVIS et G. TAYLOR [14], montre que les bulles d'air, si familières, ne sont pas du tout des sphères. Néanmoins. l'article montre que la formule de STOKES est valable. On suggère au lecteur de tracer une sphère imaginaire à l'intérieur du dôme et de considérer le mouvement relatif du matériau qui l'entoure (relatif par rapport à la vitesse moyenne de la sphère). Les relations issues du problème de STOKES sont : $\mathrm{C} \leqslant \Delta \mathrm{og}_{\mathrm{R}} / \alpha$ pour l'initialisation, où $(1 / \alpha)$ est le facteur d'efficacité de la force motrice statique ( $\sim 0,1$ dans le cas présent) et

$$
\langle\dot{\mathrm{E}}\rangle \equiv \mathrm{V} / \mathrm{R}=(\Delta \rho \mathrm{g}-(\Delta \rho \mathrm{g} / \alpha)) \mathrm{R} / \beta
$$

$1 / \beta$ est le facteur d'efficacité de la force motrice du mouvement $(1 / \beta \cong 4 / 18$ dans le cas présent).

\subsection{Cas stables}

1. Grande cellule : interface plane. Couche supérieure : $0,15 \mathrm{~m}$ d'argile chargée (mélange $\mathrm{n}^{\circ} 1$ ) : couche inférieure : $0,2 \mathrm{~m}$ de gélatine, trois fois plus résistant que le mélange ordinaire (mélange $\mathrm{n}^{\circ} 3$ ) : $8 \mathrm{~h} 37$ : $20 \mathrm{~g}^{\prime} ; 8$ h $59: 40 \mathrm{~g}^{\prime} ; 9$ h $29: 60 \mathrm{~g}^{\prime} ; 10 \mathrm{~h}: 80 \mathrm{~g}^{\prime}$; 10 h 29: 100 g'. maintenus jusqu'à 12 h 25 où l'essai a été arrêté. Pendant toute cette période, l'interface plane est restée stable.

2. Grande cellule : interface plane. Système 2 (argile chargée, mélange $n^{\circ} 1$ )/gélatine ordinaire (mélange $\left.\mathrm{n}^{\circ} 3\right): \mathrm{h}=0,15 \mathrm{~m}-22$ juillet $1985: 14 \mathrm{~h} 10$ : $20 \mathrm{~g}^{\prime} ; 14 \mathrm{~h} 20: 40 \mathrm{~g} ; 14 \mathrm{~h} 30: 50 \mathrm{~g}^{\prime} ; 14$ h 40 ; $60 \mathrm{~g}^{\prime}$; 15 h 21 : $100 \mathrm{~g}$ jusqu'à 15 h 51 .

23 juillet 1985 : 9 h 20 : 100 g' (léger effet photoélastique).

10 h 20 : spécimen démonté.

Certains exemples montrent que dans des cas apparemment stables il faut être prêt à centrifuger pendant une très longue période.

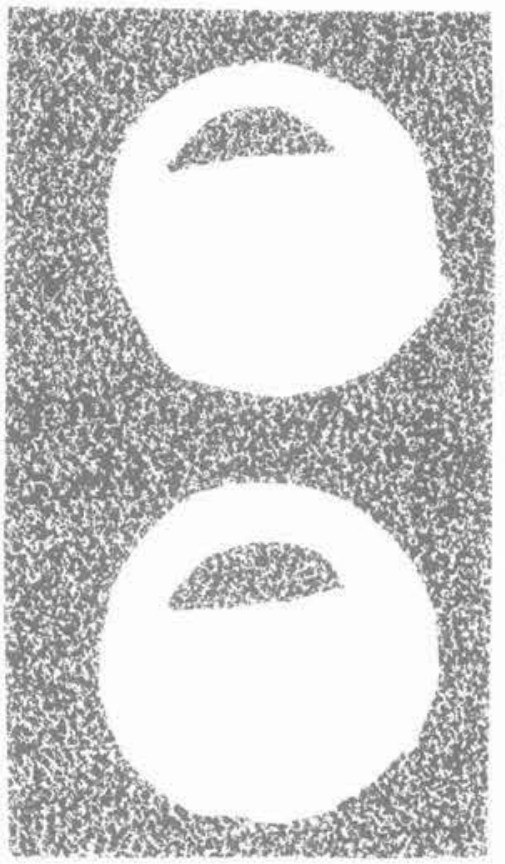

[14]

Fig. 9. - Photographies successives de la montée de bulles d'air (d'après DAVIES et TAYLOR - [14], fig. 1). Fig. 9. - Successive spark photographies of air bubbles

(after DAVIES and TAYLOR - [14] fig. 1).

\subsection{Initialisation}

\subsubsection{Interface plane, système 1 (argile-argile)}

Après une période sans événement de $1800 \mathrm{~s}$ à $100 \mathrm{~g}$ ' (qui a été précédée d'une période lente de montée en g'), le phénomène s'est produit en 1 seconde.

Les diapirs initiaux sont présentés dans la figure $6 \mathrm{~b}$. L'état final a été un renversement total de l'ordre des couches, à interface plane.

On voit que le solide lourd a formé des jets qui ont fracturé le solide léger, comme dans le cas d'une fracturation hydraulique.

\subsubsection{Initialisalisation sur une interface ondulée}

Système 1 (argile-argile), aspérité : $\mathrm{h}=5 \mathrm{~cm}$

Les étapes sont présentées sur la figure 8, pour une petite cellule et l'évolution d'un modèle dans la grosse cellule a été enregistrée (fig. 10a). Des pénétrations du matériau lourd "en tenaille» délimitent (et sur la figure 8 découpent) une zone qui flotte vers la surface. Dans le cas de la petite cellule, le moment du déclenchement n'est pas bien défini, mais supérieur à $60 \mathrm{~g}$ '. Selon la figure $10 \mathrm{a}$ la catastrophe est à $38 \mathrm{~g}$ ' avec $\Delta \rho=0,32 \mathrm{~g} / \mathrm{cm}^{3}$. 

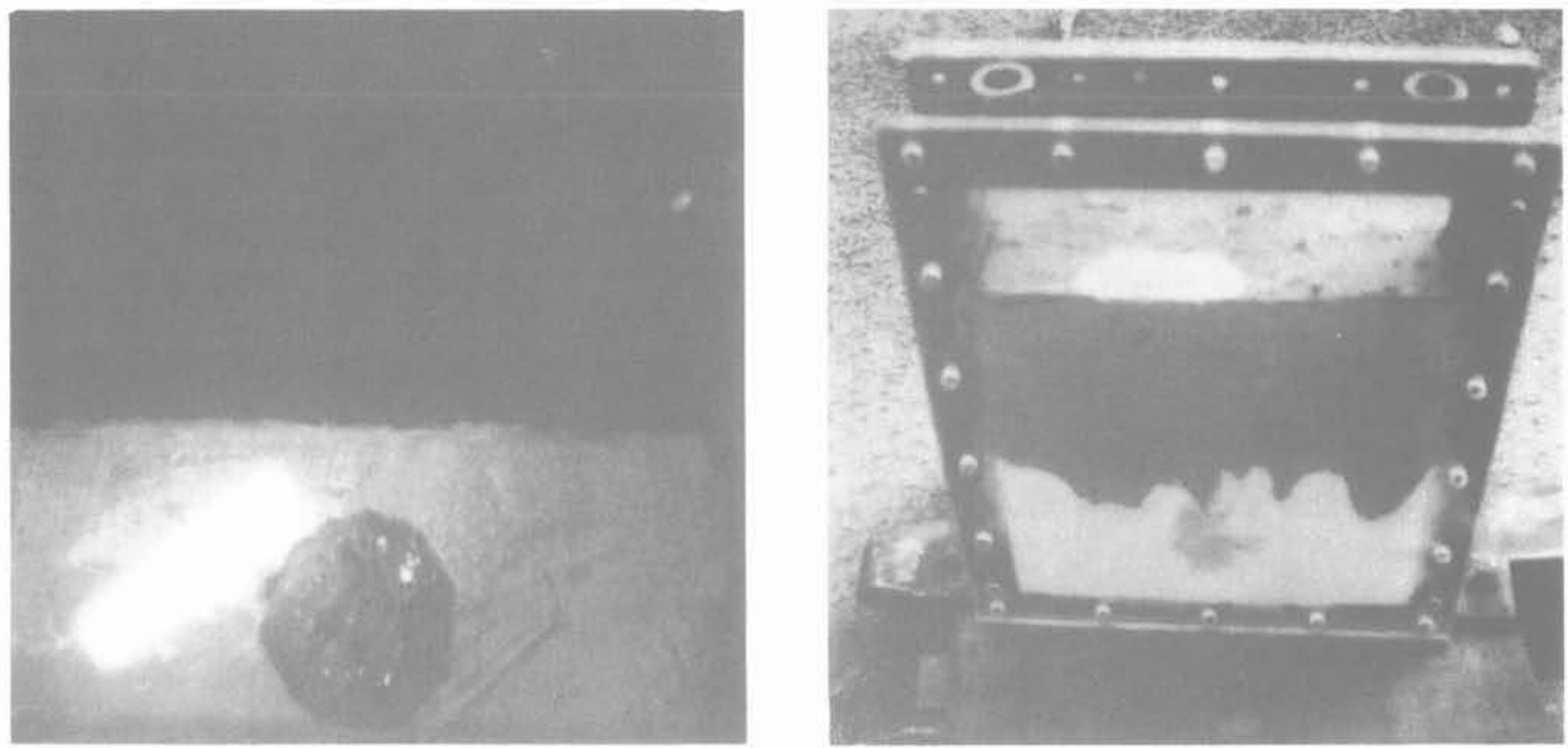

[11a]

Fig. 11. - Instabilité d'une cavité

$[11 b]$ pleine de sel affaibli.

Fig. 11. - Instability caused by a cavity full with weakened salt.

Le diamètre du dôme est de 2,5 fois celui du cylindre de STOKES (comparaison entre la figure 7 et la figure 8). Le coefficient de sécurité par rapport au cas étalon de STOKES serait alors $(0,31 / 1.4)(38 / 12)$ $(2,5 / 1)=1,75$.

Mais, si l'on tient compte du fait que l'initialisation a été déclenchée sur une autre géométrie, en prenant comme diamètre la hauteur de l'aspérité $\mathrm{h}=5 \mathrm{~cm}$, on trouve un facteur de sécurité de $(6.31 / 1,4)(38 / 12)$ $(5 / 8)=0,43$. Cette valeur est proche du cas de la fondation superficielle soumise à la charge $\Delta_{0} \mathrm{~g} h$ ou $(\Delta \rho \mathrm{g} h) / \alpha=\mathrm{C}, \alpha=\pi+2$, ce qui donne $\mathrm{C}=1100$ $\mathrm{Pa}$, dans le cas présent.

Système 2 (argile-gélatine), $\mathrm{h}=4 \mathrm{~cm}$ :

Dans ce cas $\Delta_{0}=0,56 \mathrm{~g} / \mathrm{cm}^{3}$. D'après l'enregistrement, l'initialisation est à $35 \mathrm{~g}$ '. Le rapport des forces motrices des cas $1-2$ est $(0.56 \times 35)(0.31 \times 38)=$ 1,7 , ce qui montre que la gélatine est $\sim 1,7$ fois plus résistante que l'argile. L'ordre de grandeur est correct par rapport aux mesures faites en laboratoire.

\subsubsection{Initialisation par une inclusion faible (système 3)}

La séquence des temps pour la grande cellule est donnée sur la figure $10 \mathrm{~b}$. La figure 11 présente le modèle avant et après l'initialisation dans une petite cellule.

Dans le cas de la figure 11, la couverture est renforcée selon le système 4. La catastrophe, d'après l'enregistrement, est déclenchée par une fissuration vers l'inclusion accompagnée de son écrasement, et de la formation d'un jet qui perce toutes les couches. La catastrophe est générale, selon la figure $11 \mathrm{~b}$.

\subsubsection{Initialisation sur une pente}

LEES [9] écrit que les dômes Persiques se trouvent très souvent sur les flancs des anticlinaux. L'écoulement du sel sur la pente souterraine engendre l'instabilité. La figure 12 présente un essai dans la petite cellule (système 1, argile-argile).

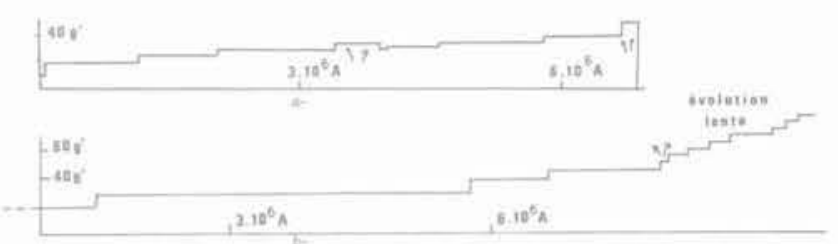

Fig. 10 - Séquences de temps.

Fig. 10. - Time sequences.

\subsection{Analyse photoélastique (système 2)}

Une analyse photoélastique complète exige une installation qui permet de faire tourner les plaques polarisantes. La centrifugeuse n'est pas équipée d'une telle installation. L'analyse est basée sur une comparaison des lignes isochromatiques (les « franges $x$ ) filmées avec celles des solutions de l'équation bi-harmonique. Il est rappelé qu'une ligne isochromatique est le lieu des points où le rayon du cercle de MOHR est constant.

\subsubsection{Initialisation sur une ondulation}

La figure 13 présente la séquence au cours du temps.

L'interface est esquissée sur la figure. Il s'agit d'une pente de $1 / 6$ des deux côtés de la fenêtre. 

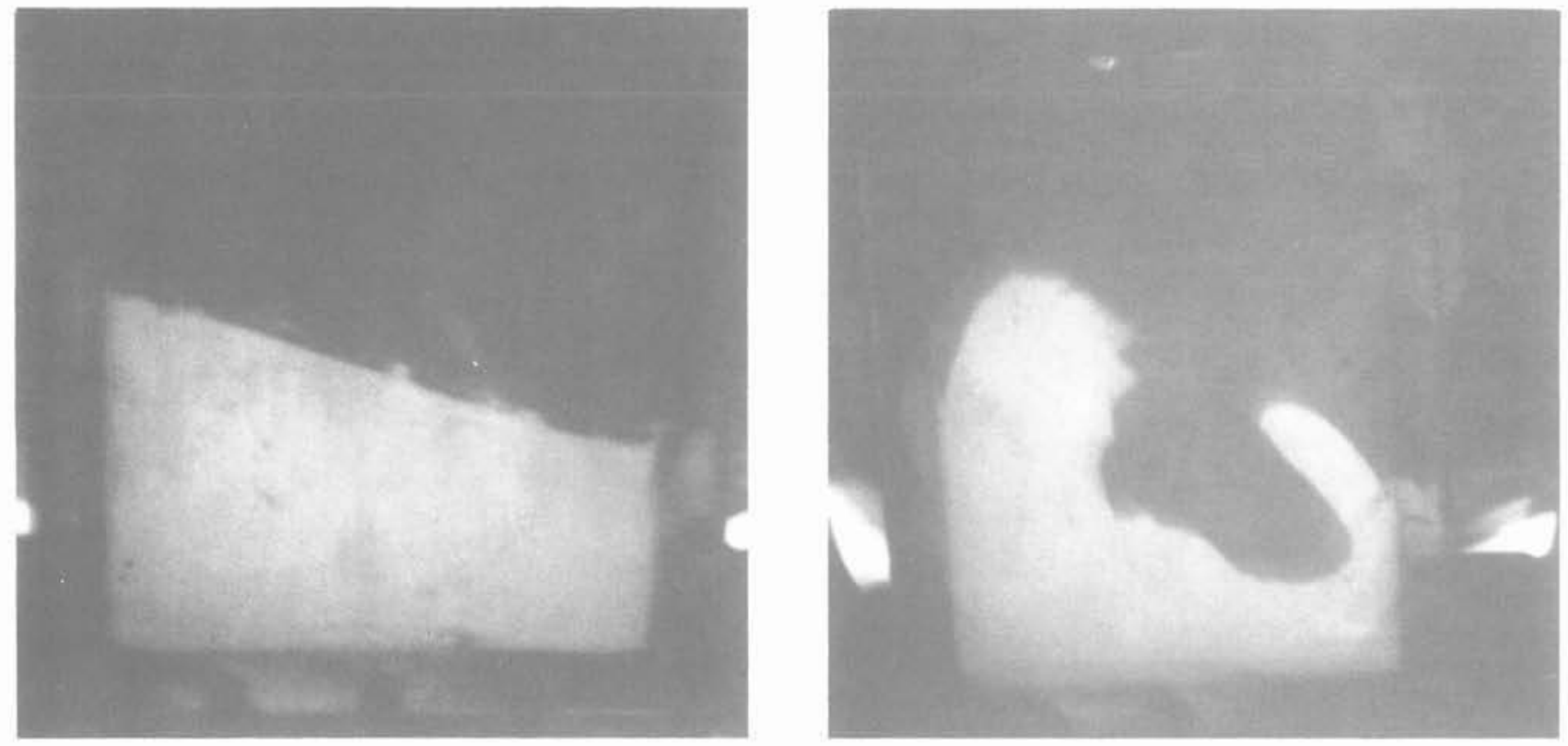

$O g$

Fig. 12. - Instabilité d'une interface inclinée.

$50 \mathrm{~g}^{\prime}$ Fig. 12. - Instability of a sloping interface.

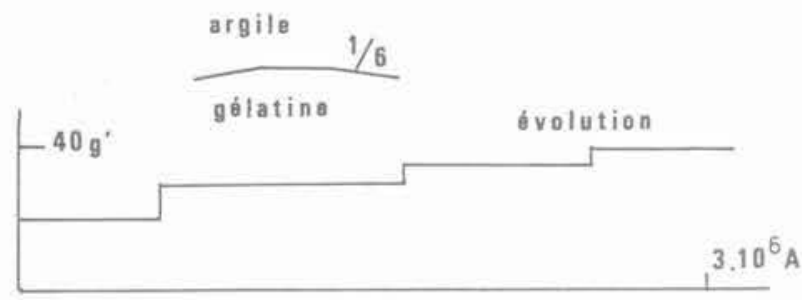

Fig. 13. - Séquence de temps pour un système argile-gélatine.

Fig. 13. - Time sequence for a clay-gelatine system.

Le régime de contraintes au début est présenté sur la figure 14 et son analyse sur la figure 15 .

La comparaison est faite avec la solution de HERTZ pour un cylindre soumis à deux lignes de forces concentrées opposées sur un diamètre. Cette solution est une superposition de trois champs:

- ligne de force à l'origine (deux fois) :

- une pression hydrostatique constante (cette pression qui n'apparaît pas sur les franges fait, dans le cas présent. partie de la charge moyenne $\rho \mathrm{g} \mathrm{H}, \mathrm{H}=$ profondeur moyenne).

La fonction d'AIRY $\Phi(\mathrm{r}, \theta)$ en coordonnées polaires est, pour le cas $1, \phi=-r \theta \cos \theta$, d'où $\sigma_{\mathrm{r}}=(2 \sin \theta) / \mathrm{r}$, $a_{i}=0, \tau=0$.

Les isochromatiques sont présentées sur la figure 15.

En agrandissant la photo de la figure 14 jusqu'à ce que la séquence de frange coïncide avec celle de la figure 15 , on trouve la valeur du rayon du cylindre et la force.
La plus intéressante est la distribution des pressions horizontales $\sigma_{x}$ dans la figure. Leur valeur est de l'ordre de $1000 \mathrm{~Pa}$, tandis que la contrainte motrice $\Delta \mathrm{p} \mathrm{g}$ h est de l'ordre de dix fois plus. Bien que l'écrasement horizontal soit le phénomène principal, l'efficacité de la force motrice verticale est de l'ordre de 1/10.

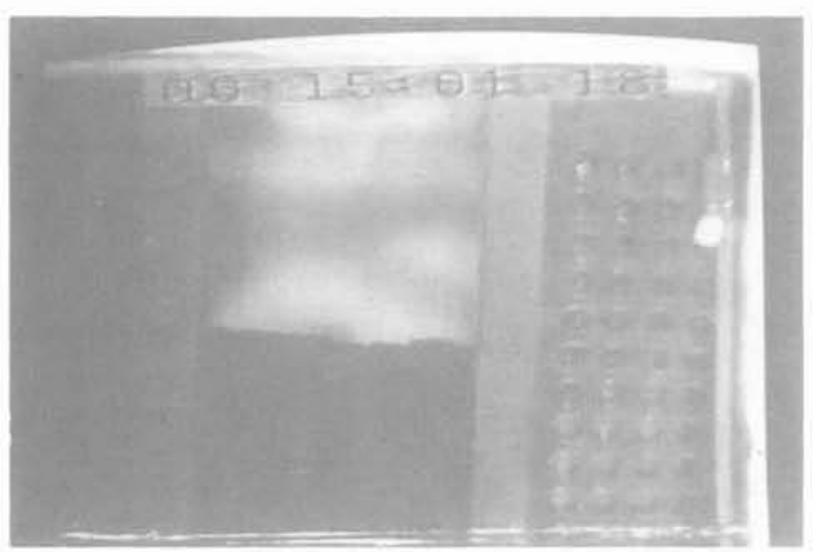

Fig. 14. - Témoignage photoélastique du commencement de la formation du dôme.

Fig. 14. - Photoelastic record of

the beginning of the dome's formation.

\subsubsection{La colonne de sel}

Un certain nombre de dômes sont semblables à une colonne qui s'agrandit en poussant les couches supé. rieures.

Un modèle avec trois diapirs initiaux de $8 \mathrm{~cm}$ a été observé dans la grande cellule. Après un écrasement horizontal, tel que le cas décrit dans le paragraphe précédent, une colonne de gélatine représentant le sel a commencé à bouger vers la surface. 


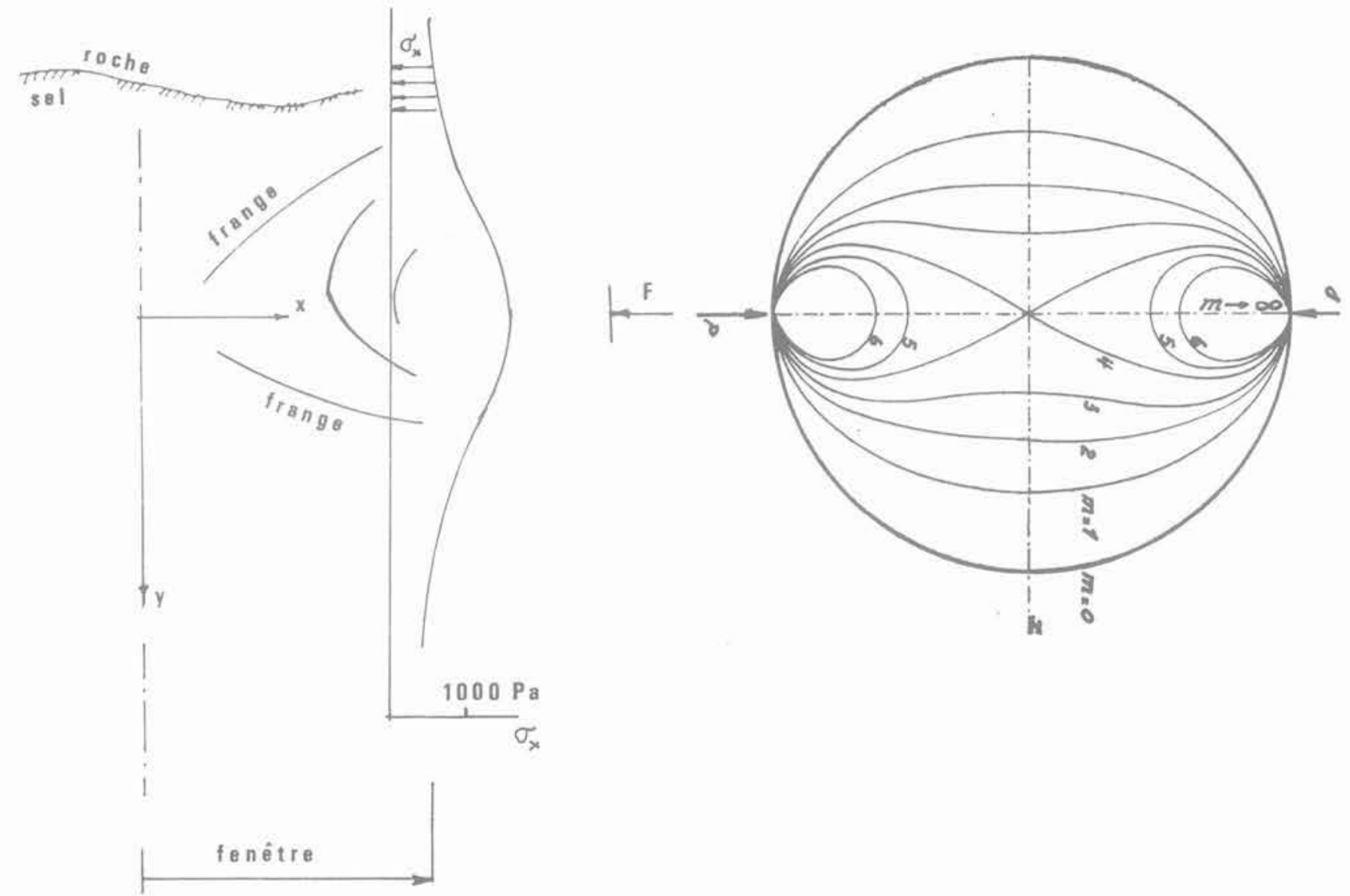

Fig. 15. - Le problème de HERTZ:

à gauche: Contraintes d'écrasement.

à droite : Franges isochromatiques.

Fig. 15. - HERTZ'S problem:

left : Pinching stresses.

right: Isochromatic fringes.

Les isochromatiques sont présentés sur la figure 16. On voit que ce sont des ellipses sur la partie haute de la colonne.

Les fonctions d'AIRY, pour ce cas, sont des polynômes en coordonnées cartésiennes. Les cas suivants sont superposés :

1. La flexion pure : la fonction d'AIRY $F$ est $F=y^{3}$ multipliée par une constante : $\sigma_{y}=0, \sigma_{x}=6 \mathrm{y}$, $\tau=0$.

2. $F=x^{2}$ y multipliée par une constante.

$$
\sigma_{\mathrm{x}}=0, \sigma_{\mathrm{y}}=2 \mathrm{y}, \tau=-2 \mathrm{x} \text {. }
$$

3. $\sigma_{\mathrm{X}}=\rho_{\mathrm{s}} \mathrm{g} \mathrm{y}, \sigma_{\mathrm{y}}=0, \tau=0$.

Cette solution vérifie l'équation d'équilibre; et :

$$
\Delta\left(\sigma_{x}+\sigma_{y}\right)=0 \text {. }
$$

La superposition est :

$$
\sigma_{\mathrm{x}}=\alpha \rho_{\mathrm{S}} \mathrm{g} y, \sigma_{i}=\left(\rho_{\mathrm{S}} \mathrm{g}+\mathrm{k}\right) \mathrm{y}, \tau=\mathrm{kx} \text {; }
$$

$\alpha$ et $\mathrm{k}$ sont constantes.
$\mathrm{Si}$, le rayon du cercle de MOHR est $\mathrm{R}$, on trouve $\left(\sigma_{x}-\sigma_{v}\right)^{2}+(2 \tau)^{2}=(2 \mathrm{R})^{2} ;\left((\alpha-1) \rho_{\mathrm{S}} \mathrm{g}+\mathrm{k}\right)^{2}$ $y^{2}+2 k^{2} x^{2}=2 R^{2}$. Ce sont les équations des ellipses isochromatiques.

Pour $y=0$, la seule contrainte non nulle est $\tau$, ce qui donne k. Le rapport des axes des ellipses donne $\alpha$. La distribution des contraintes est présentée sur la figure 16. Il s'agit de la surcharge par rapport à une contrainte hydrostatique constante.

Les valeurs correspondant à cette figure sont $\alpha=$ 1,12 , ce qui montre que la contrainte horizontale est grande relativement à la contrainte verticale $\mathrm{k}=$ $0.012 \mathrm{~N} / \mathrm{cm}^{3}$, autrement dit $\Delta \rho \mathrm{g} / \mathrm{k}=15$.

Pour des rapports de $\alpha$ plus grands, les ellipses deviennent plus plates, de sorte que dans la fenêtre on ne voit que des lignes isochromatiques parallèles, comme pour une flexion pure. Ceci a été le cas pour un modèle initialisé sur trois bosses de $\mathrm{h}=2 \mathrm{~cm}$, présenté dans le film. 

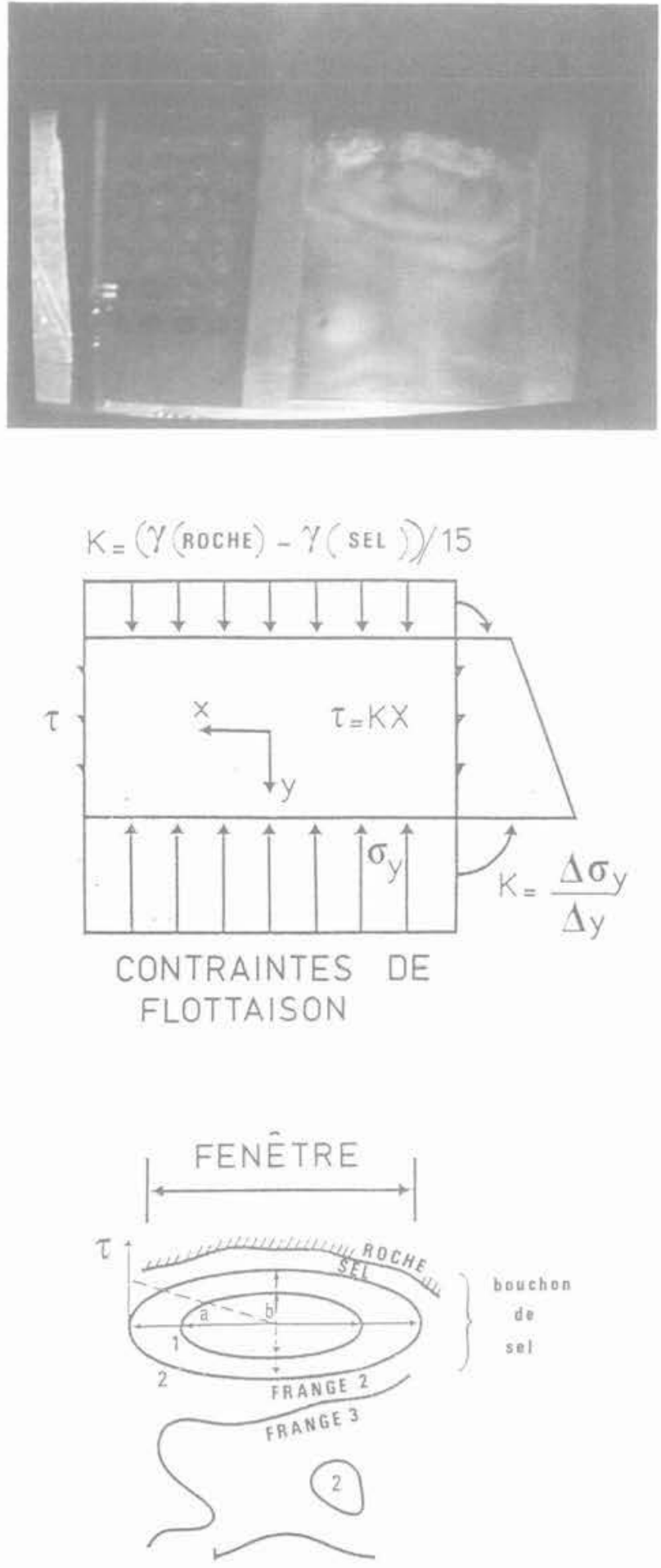

Fig. 16. - Les contraintes juste avant la ruine. Fig. 16. - The stresses an instant before ruin.

\subsubsection{Quelques conclusions de l'analyse photoélastique}

Les exemples précédents montrent que la force motrice $\Delta \rho \mathrm{g}$ est d'abord transformée en un système de forces d'écrasement horizontales, avec une efficacité de l'ordre de 1/10. Ensuite, dans le mouvement qui commence, la partie supérieure du diapir se comporte comme un bouchon poussé vers le haut par une pression verticale uniforme à sa base. Cette pression est combattue par une contrainte de cisaillement uniforme sur la paroi latérale, égale à la cohésion du sel. L'efficacité de la force motrice est de l'ordre de $1 / 15$ pour ce cas.

\subsection{Durée de l'évolution}

Les exemples d'équilibre plastique des modèles ainsi que l'analyse photoélastique permettent de prendre comme première approximation les valeurs de C présentées au début : de l'ordre de $0,3 \mathrm{MPa}$. En ce qui concerne la viscosité, WOIDT, par exemple, [15], cite $10^{15} \mathrm{~Pa}$.s $\leqslant \eta \leqslant 10^{18} \mathrm{~Pa}$.s soit une variation de 1 à 1000. Il propose $\eta=10^{17}, \mathrm{C}_{\mathrm{m}}=500 \mathrm{~Pa}$, donc $\mathrm{C}^{*}=$ $1 / 600, \eta_{\mathrm{m}}=10000 \mathrm{~Pa} . \mathrm{s}$, donc $\eta^{*}=10^{-13}$.

L'échelle du temps est :

$$
t^{*}=\eta^{*} / C^{*}=6 \times 10^{-11} .
$$

Selon cette échelle, une seconde correspond à 500 ans in situ. Cette échelle a été adoptée pour l'enregistrement ainsi que pour les séquences des figures 10 et 13 . Ces séquences montrent l'existence de périodes d'évolution très lentes avant et après la catastrophe, selon la courbe en pointillés de la figure 2 .

\subsection{Coefficient de sécurité du cas étalon}

Ayant choisi $C=0.3 \mathrm{MPa}$, on peut estimer le coefficient de sécurité du cas étalon, le cylindre de STOKES. La sécurité des autres cas a été estimée relativement à celui-ci au moyen des essais.

Pour une interface de profondeur $500 \mathrm{~m}$, par rapport à $20 \mathrm{~cm}$ dans le modèle, l'échelle de longueur est $f^{*}=1 / 2500$ et le cylindre de $8 \mathrm{~cm}$ représente $200 \mathrm{~m}$ in situ.

La contrainte motrice pour $\mathrm{R}=100 \mathrm{~m}, \Delta \rho=0,2 \mathrm{~g} / \mathrm{cm}^{3}$ est $\sigma=0,37 \mathrm{MPa}$. Le modèle donne alors $\sigma_{\sigma} \cong 13,4 \mathrm{C}$. Le coefficient de sécurité est $13,4 \times 0,3 / 0,37=11$.

Comme les cas d'initialisation étudiés dans le modèle avaient une sécurité du même ordre de grandeur que le cas étalon, on peut considérer que leur coefficient de sécurité est de l'ordre de 10 pour la profondeur de $500 \mathrm{~m}$. De la même façon, les mêmes structures sont instables à partir d'une profondeur de l'ordre de $5000 \mathrm{~m}$.

D'un autre côté, si on estime que la résistance est $\mathrm{C}=0,03 \mathrm{MPa}$, de sorte que ces structures deviennent instables à la profondeur de $500 \mathrm{~m}$, alors l'échelle du temps est dix fois plus petite de sorte qu'une seconde correspond à 5000 ans. Ceci montre les rôles que jouent la cohésion et le coefficient de viscosité dans l'estimation globale de la sécurité. 


\subsection{Le blocage de croissance}

Que se passe-t-il quand le dôme rencontre des couches relativement résistantes?

Les seuls cas étudiés consistaient à rigidifier, par un facteur dix, la moitié de l'épaisseur entre le toit du dôme et la surface libre (système 4).

\subsubsection{Couche rigide près de la surface libre}

Dans ce cas, le dôme n'a pas percé la couche rigide. Tout le phénomène s'est déroulé en profondeur malgré une augmentation du nombre de g'. L'écoulement est devenu de plus en plus tourbillonnaire tendant vers un mixage de deux matériaux.

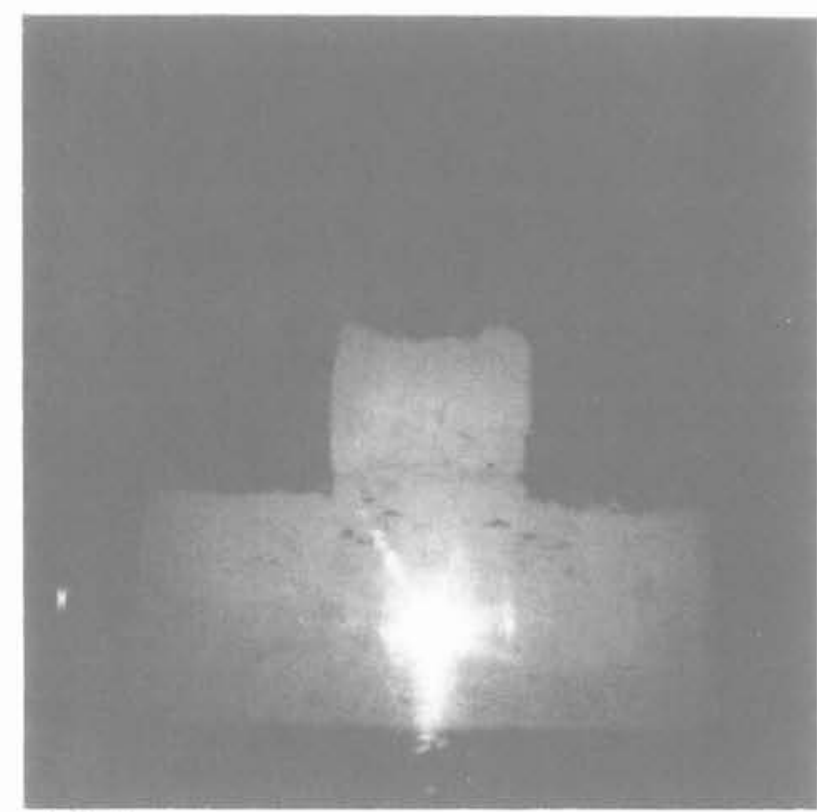

\section{a) $\mathrm{Og}^{\prime}$}

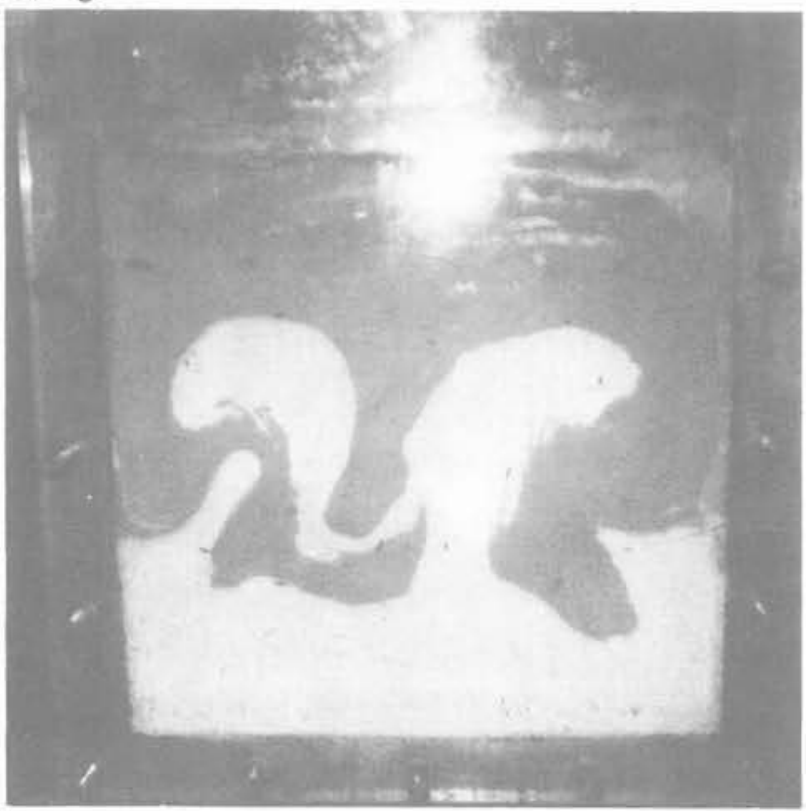

Or, un tel mixage correspond à un état géostatique méta-stable.

Les détails de ce mixage sont présentés sur la figure 17. On note que c'est le matériau lourd qui a coulé dans le matériau léger, tandis qu'une flottaison du matériau léger vers la surface n'a pas eu lieu. Dans la phase finale (figure $17 \mathrm{~d}$ ), tout s'arrête à mi-hauteur du modèle. In situ, de telles évolutions risquent d'échapper à une auscultation à partir de la surface.

6.7.2. Couche rigide en contact avec le toit du dôme

Le système est le même que dans le cas précédent, sauf que la couche rigide à changé de position. Le

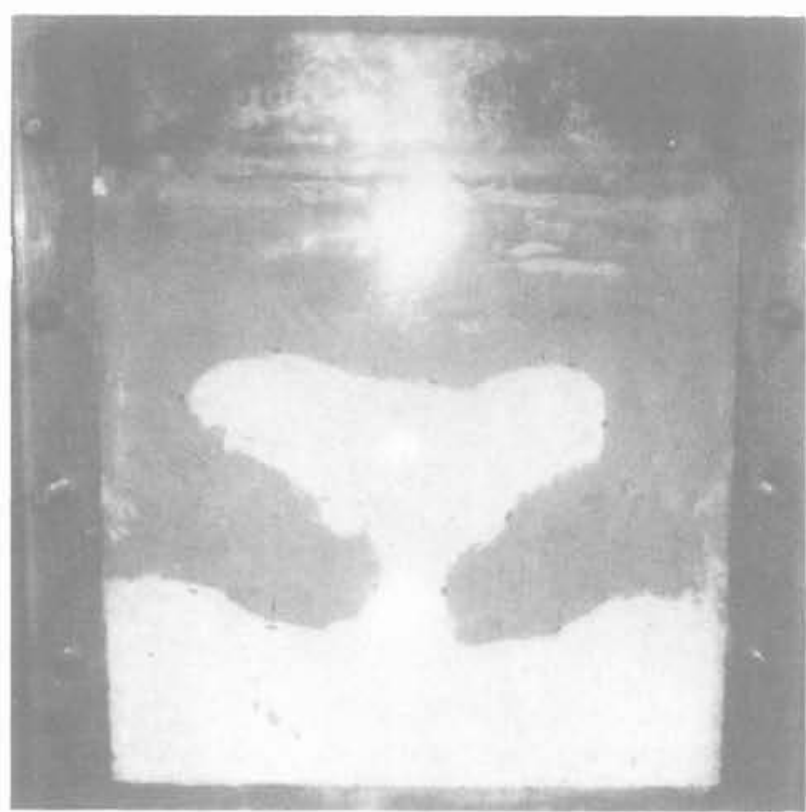

b) $40 \mathrm{~g}$

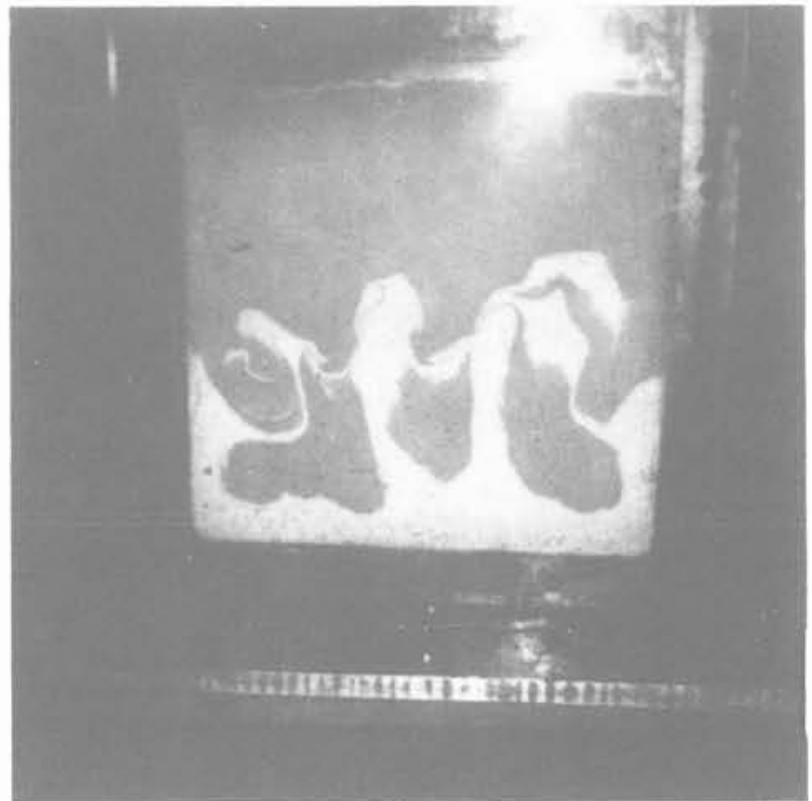

d) $100 \mathrm{~g}$

c) $60 \mathrm{~g}^{\prime}$

Fig. 17. - Mixage sous une couche rigide.

Fig. 17. - Mixing below a rigid layer. 


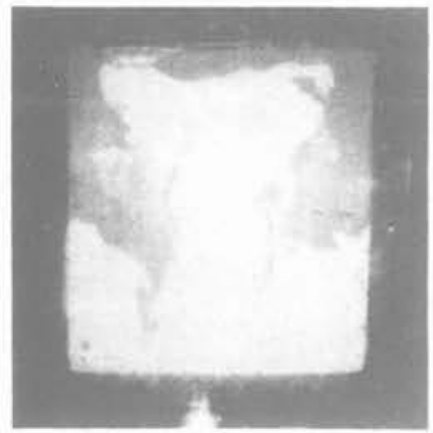

a)

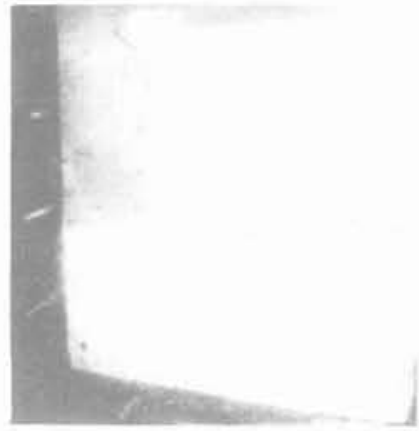

b)

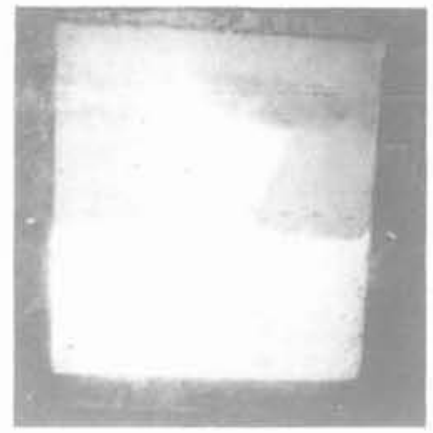

c)

Fig. 18. - Perçage d'une couche rigide.

Fig. 18. - Piercing of a rigid layer.

comportement est totalement différent du cas précédent (fig. 18). La couche rigide bloque le mouvement vertical (figure 18a), tandis que l'écrasement horizontal est possible. La poussée du dôme casse la couche rigide en trois morceaux comme une poutre se rompt avec trois articulations (figure 18b). Un morceau reste sur le toit tandis que les deux autres sont pliés dans une position verticale des deux côtés du « champignon » et, finalement, sont incorporés dans le tronc de celui-ci (figure 18c). La forme finale est similaire à plusieurs cas rencontrés in situ. La colonne finale est issue d'une évolution du voisinage de la surface, et non pas d'un jet.

L'essai a été répété dans la grande cellule et l'évolution suivie à partir de 25 g', ce qui a amené à la rupture.

La différence dans les comportements des cas 6.7.1. et 6.7.2, et la forme de la rupture de ce dernier cas laissent à penser que le paramètre principal est la résistance à la traction, comme si la couche rigide faisait " armature " pour la couverture. On sait que pour une poutre en béton l'armature est du côté de la traction maximale. La sécurité peut donc être estimée selon le champ cinématiquement admissible habituel des poutres encastrées: trois articulations de moment critique $\mathrm{M}_{\mathrm{c}}=\mathrm{q} l^{2} / 16 .(\mathrm{q}=$ charge $; l=$ largeur ; $\mathrm{M}_{\mathrm{rr}}=\mathrm{CH}^{2} / 2, \mathrm{H}$ : hauteur de la poutre). Dans le cas présent: $\mathrm{H}=$ la profondeur du toit $=10 \mathrm{~cm}$. $\mathrm{C}=500 \mathrm{~Pa}$ (la résistance de la couche rigide) : $\mathrm{M}=$ $1,25 \mathrm{Nm} / \mathrm{m}$. Si $l$ est la largeur du dôme, soit $0.2 \mathrm{~m}$, on trouve $\mathrm{q}=1,25 \times 16 / 0,2^{2}=500 \mathrm{~Pa}, \Delta p \cong$ $0,4 \mathrm{~g} / \mathrm{cm}^{3}$ et à $25 \mathrm{~g}$ ' la contrainte motrice $\sigma$ sur toute la hauteur du dôme $\mathrm{h}(\mathrm{h}=0,1 \mathrm{~m})$ est $\sigma=\Delta \rho \mathrm{g} h=$ $10000 \mathrm{~Pa}=20 \mathrm{q}$.

Comme c'est un modèle cinématiquement admissible l'efficacité de la force motrice est minorée par 1/20.

Dans le cas où le dôme n'a pas percé, on prend $\mathrm{C}=5000 \mathrm{~Pa}$, ce qui donne $\mathrm{M}_{\mathrm{ct}}=12,5 \mathrm{Nm} / \mathrm{m}$ et $\mathrm{q}=5000 \mathrm{~Pa}, \sigma \cong 2 \mathrm{q}$ et n'a pas suffit pour percer.

Il semble donc qu'une utilisation du champ de mouvement à trois articulations et d'une charge $q \cong \sigma / 10=$ $\Delta \rho \mathrm{g} h / 10$ donnerait une estimation convenable pour la sécurité.

\subsection{Essais d'un modèle DAUBRÉE (jet d'argile)}

Les essais sur centrifugeuse montrent que dans plusieurs cas le dôme est un * champignon " nourri par un

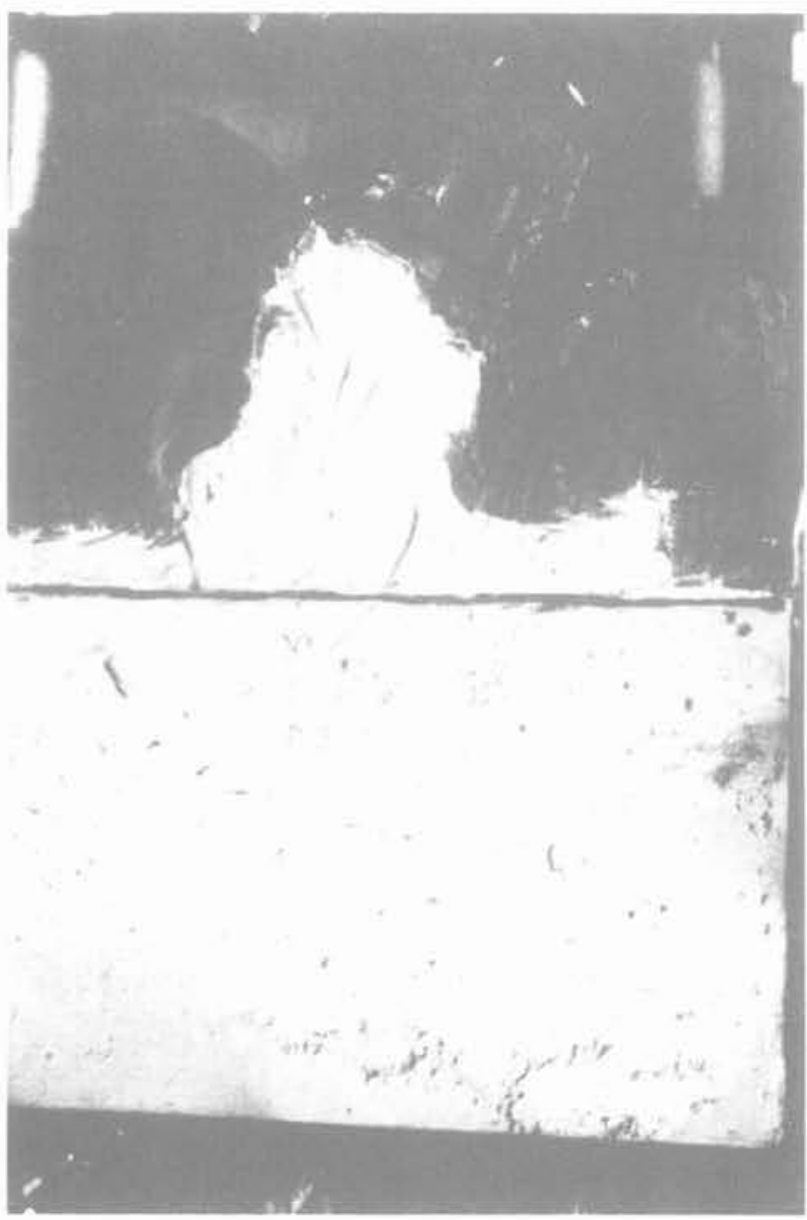

Fig. 19. - Jet perçant la couche supérieure. Essai sous presse.

Argiles non chargées à la limite de liquidité.

Fig. 19. - A jet piercing the upper layer. Tests on a press.

"Unloaded" clay at the limit of liquidity. 
jet. Ce jet est formé par l'écrasement en tenaille d'une partie de la couche inférieure. Ce phénomène peut être imité en laboratoire, bien entendu sans que la similitude puisse être garantie. On place une cloison rigide trouée entre les deux argiles, et on exerce par une presse sur la cloison la force correspondante à la différence des pressions dans l'essai centrifugé. L'essai se déroule très lentement (un micron par seconde). La couche supérieure est en effet percée par le jet. Elle est fortement fissurée et se casse en blocs; comme dans le cas de la couche rigide de la figure 18. Des lignes de LUDERS apparaissent dans la zone inférieure qui nourrit le jet. Sur la figure 19, on peut les voir au moyen d'une loupe. Elles correspondent bien au schéma des lignes de glissement des fondations.

\section{CONCLUSIONS}

Les grands modèles, de dimensions de l'ordre de $1 \mathrm{~m}$ et les installations embarquées sur la centrifugeuse ont permis une observation détaillé des différents modèles diapiriques. Les résultats de tous ces modèles constituent un ensemble cohérent qui peut être interprété par les calculs de charge limite de la théorie de plasticité. Les résultats photoélastiques confirment ces interprétations, notamment en ce qui concerne l'efficacité de la charge motrice.

L'application d'une loi de comportement solide (BINGHAM) permet de définir une échelle de contrainte et une échelle de temps. La sécurité pour qu'un système soit stable est non nulle, contrairement au cas d'une loi de comportement fluide. Cette sécurité est estimée par comparaison avec une structure étalon : le cylindre de STOKES flottant vers la surface. Cette sêcurité dépend de l'échelle de longueur.

\section{Remerciements :}

Le travail présenté a fait l'objet d'un contrat de la Communauté Européenne passé par l'intermédiaire de l'Agence Nationale pour la Gestion des Déchets Radioactifs (A.N.D.R.A.).

\section{RÉFÉRENCES}

1. THOM R., Stabilité structurelle et morphogenèse, W.A. Benjamin, Massachussetts, U.S.A. 1972.
2. BUCKY P.B., Effect of Approximately vertical Cracks on the Behaviour of Horizontally lying Roof Strata, Trans. Am. Inst. Min. and Metal. Eng., vol. 109, pp. 212-229, 1934.

3. SINCLAIR, DAVID and BUCKY P.B., Photoelasticity and its Application to Mine Pillar and Tunnel Problems, Trans. Am. Inst. Ming. Eng., vol. 139, pp. 225-252, 1940.

4. RAMBERG H., Instability of layered systems in the field of gravity, Phys. Earth. Planet. Interiors, vol. 1, pp. 427-447, 1968.

5. DOBRIN M.B., Some Quantitative experiments on a fluid salt dome model and their Geological implications, Trans. Amer. Geoph. Union, Vol. 22, p. 528-642, 1941.

6. NETTLETON L.L., Fluid Mechanics of Salt Domes, Bull. Amer. Inst. Petr. Geol., vol. 18, pp. $1175-1204,1934$.

7. HUBBERT M.K., Theory of scale models as applied to the study of geological Structures, Bul. Geol. Soc. of Amer., vol. 48, pp. 1459-1520, 1937.

8. GALILEI G., Dialogues concerning two new sciences, pp. 130-131, Macmillan New York, 1914.

9. LEES G.M., Salt-Some deposition and Deformational Problems, Int. J. Pet. Tech., vol. 17, pp. 259-279, 1931.

10. GUSSOW W.C., Salt diapirism : Importance of Temperature and Energy source of Emplacement, Proc. Amer. Assoc. Pet. Geologists Tulsa, Oklahoma, pp. 16-52, 1968.

11. DAUBRÉE A., Études systématiques de géologie expérimentale, Éd. Dunod, Paris, 1879.

12. TAYLOR G., The instability of liquid surfaces when accelerated in a direction pependicular to their planes, Proc. Roy. Soc. London, vol. 201. 1950.

13. HADAMARD J., Mouvement permanent lent d'une sphère liquide et visqueuse dans un liquide visqueux, C.R.A.S., vol. 152, pp. 1735-1739, 1911.

14. DAVIES R.M., TAYLOR G., The mechanics of large bubbles rising through extended liquids and through liquids in tubes, Proc. Roy. Soc., London, vol. 200, pp. 375-388, 1950.

15. WOIDT W.D., Finite element calculations applied to salt dome analysis, Tectonophysics, vol. 50 , pp. 369-386, 1978. 